\title{
A mechanistic model for long-term nuclear waste glass dissolution integrating chemical affinity and diffusion barrier \\ DOI:
}

10.1016/j.jnucmat.2017.01.001

\section{Document Version}

Accepted author manuscript

Link to publication record in Manchester Research Explorer

Citation for published version (APA):

Ma, T., Jivkov, AP., Li, W., Liang, W., Wang, Y., Xu, H., \& Han, XY. (2017). A mechanistic model for long-term nuclear waste glass dissolution integrating chemical affinity and diffusion barrier. Journal of Nuclear Materials, 486, 70-85. https://doi.org/10.1016/j.jnucmat.2017.01.001

\section{Published in:}

Journal of Nuclear Materials

\section{Citing this paper}

Please note that where the full-text provided on Manchester Research Explorer is the Author Accepted Manuscript or Proof version this may differ from the final Published version. If citing, it is advised that you check and use the publisher's definitive version.

\section{General rights}

Copyright and moral rights for the publications made accessible in the Research Explorer are retained by the authors and/or other copyright owners and it is a condition of accessing publications that users recognise and abide by the legal requirements associated with these rights.

\section{Takedown policy}

If you believe that this document breaches copyright please refer to the University of Manchester's Takedown Procedures [http://man.ac.uk/04Y6Bo] or contact uml.scholarlycommunications@manchester.ac.uk providing relevant details, so we can investigate your claim.

\section{OPEN ACCESS}




\section{Accepted Manuscript}

A mechanistic model for long-term nuclear waste glass dissolution integrating chemical affinity and interfacial diffusion barrier

Teqi Ma, Andrey P. Jivkov, Weiping Li, Wei Liang, Yu Wang, Hui Xu, Xiaoyuan Han

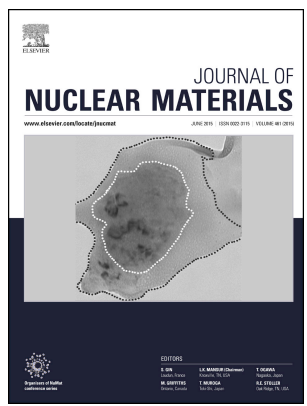

PII:

S0022-3115(17)30011-9

DOI:

10.1016/j.jnucmat.2017.01.001

Reference: NUMA 50061

To appear in: Journal of Nuclear Materials

Received Date: 14 November 2015

Revised Date: 26 November 2016

Accepted Date: 2 January 2017

Please cite this article as: T. Ma, A.P. Jivkov, W. Li, W. Liang, Y. Wang, H. Xu, X. Han, A mechanistic model for long-term nuclear waste glass dissolution integrating chemical affinity and interfacial diffusion barrier, Journal of Nuclear Materials (2017), doi: 10.1016/j.jnucmat.2017.01.001.

This is a PDF file of an unedited manuscript that has been accepted for publication. As a service to our customers we are providing this early version of the manuscript. The manuscript will undergo copyediting, typesetting, and review of the resulting proof before it is published in its final form. Please note that during the production process errors may be discovered which could affect the content, and all legal disclaimers that apply to the journal pertain. 


\title{
A mechanistic model for long-term nuclear waste glass dissolution integrating chemical affinity and interfacial diffusion barrier
}

\author{
Teqi Ma ${ }^{\mathrm{a}, \mathrm{b}}$,Andrey P Jivkov ${ }^{\mathrm{b}^{*}}$,Weiping Li ${ }^{\mathrm{a}}$, Wei Liang ${ }^{\mathrm{a}}$, Yu Wang ${ }^{\mathrm{a}}$, Hui Xu ${ }^{\mathrm{a}}$, Xiaoyuan Han ${ }^{\mathrm{a}}$ \\ ${ }^{a}$ Northwest Institute of Nuclear Technology, No.28 Pingyu Road, Baqiao District, Xi' an,Shaanxi, 710024, China \\ ${ }^{\mathrm{b}}$ Mechanics and Physics of Solids Research Group, Modelling and Simulation Centre, The University of Manchester, Oxford \\ Road, Manchester, M13 9PL, UK
}

\begin{abstract}
:
Understanding the alteration of nuclear waste glass in geological repository conditions is critical element of the analysis of repository retention function. Experimental observations of glass alterations provide a general agreement on the following regimes: inter-diffusion, hydrolysis process, rate drop, residual rate and, under very particular conditions, resumption of alteration. Of these, the mechanisms controlling the rate drop and the residual rate remain a subject of dispute. This paper offers a critical review of the two most competitive models related to these regimes: affinity-limited dissolution and diffusion barrier. The limitations of these models are highlighted by comparison of their predictions with available experimental evidence. Based on the comprehensive discussion of the existing models, a new mechanistic model is proposed as a combination of the chemical affinity and diffusion barrier concepts. It is demonstrated how the model can explain experimental phenomena and data, for which the existing models are shown to be not fully adequate.
\end{abstract}

Key words: nuclear waste glasses, long-term dissolution, mechanisms, modelling

\section{Introduction}

Radioactivity wastes are generated at all stages of the nuclear fuel cycle, including the decommissioning of nuclear facilities, as well as from military applications. Of particular concern for the storage/disposal of radioactivity wastes are those containing long-lived radionuclides[1].The current plan ( countries such as Belgium, Finland, Sweden, France etc.)for long-term management of such wastes is to store them in deep, stable and lowpermeable geological formations[2].The storage design is based on the so-called multi-barrier concept, where several barriers prevent for a period of time, or slow down the release and migration of radionuclides through the geosphere[3,4].Within this concept, hazardous nuclides are immobilized into solidified bodies. The wasteform selection is difficult, since durability is not the sole criterion[5]. Currently, vitrification is regarded as the best solution for immobilizing radionuclides. This technology has been progressively developed over the last half-century, has matured and has become industrially robust.

Data collected to date suggest that glass waste forms offer the advantages that they can accommodate a wide range of waste streams, are resistant to radiation damage, and are relatively inert to both chemical and thermal perturbations[6].The use of natural and archeological analogues supported further the durability argument of glass as waste forms[711]. Except for the alumino-phosphate glass used in Russia, the borosilicate glass has been universally selected by all other nations[12].

In order to make scientifically-underpinned safety cases, the long-term behaviour of glassy wasteforms requires further understanding and assessment. Half-lives of some radionuclides extend to millions of years, requiring isolation for geological periods, while the period of investigation possible in the field and the laboratory is relatively short.The development of reliable performance assessment models must be based on a rational consensus on the mechanisms controlling the long-term dissolution of glass.

*Corresponding author, E-mail address:andrey.jivkov@manchester.ac.uk, xyhan_nint@ sina.cn 
Experimental observation is that the dissolution rate of nuclear waste glass decreases with increasing time of exposure, only if the Si concentration in solution increases or an alteration layer is formed. The interpretations of this currently relate either to a thermodynamically (chemical affinity) or to a kinetically controlled dissolution behaviour (diffusion barrier). However, models based on these concepts yield quite different long-term predictions, even though they fit equally well particular sets of experimental data[13, 14,15].

This work presents a new model, which combines the two previous approaches. Firstly, the aqueous alteration regimes of nuclear waste glass and related dominant mechanisms are reviewed briefly. This is followed by a discussion on the rate drop and residual rate controlling mechanisms, leading to the new model. It is used to interpret the key experimental observations found in the literature.

\section{Mechanisms and models of long-term glass dissolution: consensus and arguments}

The vitrification process creates chemical bonds between radionuclides and the nuclear waste glass network. Consequently, the radionuclides cannot be released if the glass remains undissolved. For the purpose of "source term" estimation, it is essential to clarify the longterm dissolution behaviour of nuclear waste glasses.

The dissolution of glass is a complex process that depends on both the intrinsic properties of the glass and the leaching conditions. When glass comes into contact with water, processes of interdiffusion, ion exchange, reaction diffusion and hydrolysis occur. These processes and their interactions of nuclear glass alteration generally involving five rate regimes, as shown in Fig.1 [12, 16, 17]): I. Initial diffusion or interdiffusion; II. Hydrolysis process; III. Rate drop; IV. Residual rate; and V. Possible resumption of alteration in particular conditions.

These observations of the alteration kinetics, determined from concentration variations of the mobile elements(boron, alkali metals, $\mathrm{Si}$ etc.)in solution, as well as solid phase observations which were determined by modern experimental techniques such as SEM, TEM, Raman etc., can be related to the nature of the underlying mechanisms.

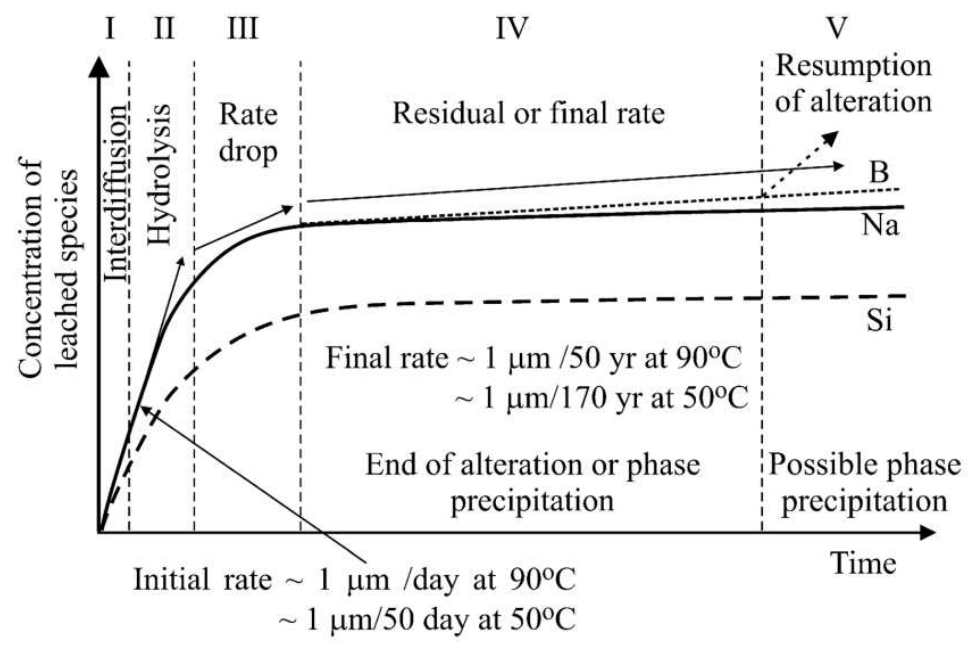

Figure 1. Time sequence of different rate regimes with sodium,boron and silicon concentrations in solution[16]

\subsection{Initial diffusion or interdiffusion}

The term interdiffusion refers to the exchange between glass network-modifier cations and protons in solution. At the very beginning of corrosion, water species penetrate into 
glass, protons in the solution undergo diffusional ion exchange with mobile alkali modifier ions such as $\mathrm{Li}^{+}, \mathrm{Na}^{+}$, leaving an alkali-depleted zone at the glass surface, called diffusion zone. This reaction can be divided into two parallel processes: water penetration into glass[18-22] and alkali ions release into solution[23, 24]. The mechanism has been identified experimentally during leaching of many minerals and natural glasses, especially in acidic media[17].

If only alkali ions were released into solution through the ion exchange reaction, the glass would remain in its glassy state. However, works with borosilicate glass have shown that the release of boron is practically congruent to those of alkali ions[15, 24], and B is the network former element. Geneste[25] investigated hydrogen-sodium interdiffusion in borosilicate glasses from first principles, using density functional calculations. They found that the substitution of the $\mathrm{Na}^{+}$network modifiers does not alter the glass covalent network, whereas a bridging bond is systematically broken when the substitution involves $\mathrm{Na}^{+}$ions bonded to $\mathrm{BO}_{4}$ tetrahedra. The systematic dissociation of hydronium into water suggests that this chemical species probably has a short lifetime in the glass, due to the capability of anionic sites to trap the protons very strongly. That is to say, the substitution of $\mathrm{Na}^{+}$ions would lead to the collapse of $\mathrm{BO}_{4}$ tetrahedra, and result in the rapid release of boron into solution.

Water diffusion and glass modifier diffusion, including $\mathrm{B}$ and alkali ions, are two parallel processes, and the slower of the two is rate limiting. It's reasonable to consider water diffusion as rate limiting, because in the opposite case one would expect large difference in the release properties of alkali ions and of B. In fact congruent release of alkali ions and B is often observed during leaching experiment[13].

\subsection{The hydrolysis process}

The initial stage, where the corrosion rate is relatively constant and at a maximum, is also referred to as the forward rate stage. This occurs before the solution reaches saturation with the silica phases occurring in the time of the experiments, such as chalcedony or amorphous silica, at which point the corrosion has been observed to decrease markedly. It also occurs before any significant development of a leached layer can form. Initial rate involves the hydrolysis of covalent and iono-covalent $\mathrm{Si}-\mathrm{O}-\mathrm{M}$ bonds $(\mathrm{M}=\mathrm{Si}, \mathrm{Al}, \mathrm{Zr}, \mathrm{Fe}$, Zn,etc.), which constitute the net structure of a glass[12, 17, 21]. Hydrolysis modifies the silicate network by attacking bridging bonds $(\mathrm{Si}-\mathrm{O}-\mathrm{Si}, \mathrm{Si}-\mathrm{O}-\mathrm{Al}, \mathrm{Si}-\mathrm{O}-\mathrm{Zr}$, etc.) in the interphase created by the release of mobile elements. Water molecules thus act on the glass by directly affecting network connectivity, leading to matrix dissolution according to the reaction: $\equiv \mathrm{Si}-\mathrm{O}-\mathrm{Si} \equiv+\mathrm{H}_{2} \mathrm{O} \rightarrow 2 \equiv \mathrm{Si}-\mathrm{OH}$. The rupture of all bridging bonds(1 4) around a silicon atom in the glass, leads to the release of an orthosilicic acid molecule, $\mathrm{H}_{4} \mathrm{SiO}_{4}$. The hydrolysis reaction has been observed to accelerate in both acid and basic conditions, with a lowest rate in neutral environment[26, 27]. Based on the first principles, it has been found[28-33] that the activation energy of the hydrolysis of $\mathrm{T}^{\mathrm{m}}-\mathrm{O}-\mathrm{T}^{\mathrm{n}}$ (where $\mathrm{T}=\mathrm{Si}, \mathrm{Al} ; \mathrm{m}, \mathrm{n}=$ number of bridge oxygen atoms and $0<\mathrm{m}, \mathrm{n}<4$ ) bonds can be rather variable: lower in acid and basic conditions but higher in neutral conditions.

In dilute solution with low $\mathrm{Si}$ concentration, the initial dissolution rate depends essentially on the temperature, $\mathrm{pH}$ and glass composition. Some ions, such as aluminium and iron, can catalyze or inhibit these kinetics[33]. For borosilicate glasses, the initial dissolution rate, $\mathrm{r}^{0}$, was determined as a function of the $\mathrm{pH}$ and the temperature according to[34]:

$$
r^{0}=k_{+}\left[H^{+}\right]^{n} \exp \left(\frac{-E_{a}}{R T}\right)
$$


where $k_{+}$is the pre-exponential factor $\left(\mathrm{g} \cdot \mathrm{m}^{-2} \cdot \mathrm{d}^{-1}\right) ; n$ is the $\mathrm{pH}$ dependence coefficient, $E_{a}$ is the activation energy of hydrolysis of $\mathrm{Si}-\mathrm{O}-\mathrm{M}$ bonds $\left(\mathrm{kJ}^{\mathrm{m}} \mathrm{mol}{ }^{-1}\right)$. Notably, the $E_{a}$ does not relate to a specific bond, but is the average or equivalent apparent activation energy.

The relation between the initial dissolution rate and the structural properties of the glass has been the subject of a number of works. Notable are the thermodynamic models based on the standard enthalpy of formation of the oxide depending on the free enthalpy of glass hydration-FEH models[35-37], and its advanced formulation - the THERMO models[38, 39]. Such models attempt to clarify the relations between glass composition, free enthalpy of glass hydration and the glass durability(expressed as dissolution rate), and point out that there is a linear relation between $\Delta \mathrm{G}$ (free enthalpy of glass hydration) and $\log r^{0}$. However, these can neither describe the dissolution rate change as a function of time nor allow for the existence of a hydrated and dealkalinized surface layer.

\subsection{Rate drop and residual rate}

The rate drop is a transition between the initial and residual rates due to the progressive saturation of the solution with silica and/or the formation of various surface layers that could impact continued corrosion. Here, we discuss rate drop regime together with the residual rate. The rate drop is the most complex kinetic regime, and its potential effect in predictive models is significant, as the corrosion rate decreases several orders of magnitude in comparison to the initial rate. The rate drop is first observed when the dissolved silicon in solution reaches a sufficient concentration, a fraction of the dissolved silicon recondenses to form an amorphous, porous, hydrated phase. The saturation of the solution with silica and/or the amorphous phase formation leads to progressive rate reduction until glass dissolution rate reaches a relatively constant value(residual rate), which is several magnitudes lower than the initial rate. There is no general agreement on the cause of this rate reduction. Two theories suggest that it is due to:(a) chemical affinity change[13, 42-47]; and(b) diffusion barrier effect[14, 15, 48, 51-54], or the combination of both[17, 49, 50].

According to the chemical affinity concept, the driving force for glass alteration is the difference between the affinities of amorphous silica(or silica polymorph) and the silicon species(such as orthosilicic acid) in the solution at saturation. At the beginning of alteration(far from equilibrium), the affinity is maximum, providing the forward rate; as the component of glass(especially $\mathrm{Si}$ ) is released into the solution and the concentrations building up, the chemical affinity becomes progressively smaller, providing the rate drop; when the concentration of component near saturation(near equilibrium), the chemical affinity is minimum, relate to the residual rate. It should be noted that the residual rate can be very small, but not zero.

According to the diffusion barrier concept, during glass alteration, a PRI(passivating reaction interface) layer forms and creates a barrier between pristine glass and solution, limiting the mass exchange. The properties of this layer depend on both glass composition and leaching conditions, resulting in different protective effects[51, 53]. Some researchers[55] argue that a passive layer develops almost immediately, i.e. the layer exists during the forward rate regime, but with weak passivating property. In batch systems, however, it is difficult to distinguish between diffusion-limited and near-equilibrium dissolution rates.

In order to assess the realism of the two concepts, we discuss models based on both, highlighting their advantages and disadvantages. This will lead to the newly proposed model in the next section.

\subsubsection{First order dissolution law and models based on "chemical affinity"}

Early work of "chemical affinity" was based on Transition State Theory(TST) leading to the Aagaard and Helgeson's kinetic law proposed in the early 1980s[42-44]. Although TST is 
generally appropriate for elemental reactions, it has been argued that if a complex mechanism is rate-limited by a single elementary reaction, then TST could be confidently applied to the overall reaction. Different dissolution behaviours, as defined by changes in solution composition with time, are observed under far-from and near-equilibrium conditions. Glass network hydrolysis is considered as the rate limiting reaction in the following rate law[42]:

$$
\frac{d n_{i}}{d t}=A x_{i} k_{r} \prod_{j} a_{j}^{-n}\left(1-e^{\left(-\frac{A_{f}}{\sigma R T}\right)}\right)
$$

where $n_{i}$ is the number of moles of species $i$ in solution released from the glass; $t$ is the time; $A$ is the reactive surface area of glass; $x_{i}$ is the concentration of species $i$ in the glass; $k_{r}$ is the rate coefficient for the rate-limiting reaction for glass dissolution; $\prod_{j} a_{j}^{-n}$ is the product of the activities(concentrations) of dissolved aqueous species which contributes to the activated complex of the rate-limiting microscopic dissolution reaction; $A_{\mathrm{f}}$ is the reaction affinity, defined as $\mathrm{RT} \ln (\mathrm{Q} / \mathrm{K})$, where $\mathrm{Q}$ is the activity product and $\mathrm{K}$ is the equilibrium constant for the rate-determining glass dissolution reaction; $\sigma$ is a stoichiometric factor that relates the rate-controlling microscopic reaction to the overall solid dissolution reaction(usually it is assumed $\sigma=1) ; \mathrm{R}$ is the universal gas constant and $\mathrm{T}$ is the temperature in Kelvin.

The form of Eq.(2) predicts that the dissolution rate of solids will have the following characteristics: (1) the amount of solid dissolved will be proportional to exposed surface area;(2) the dissolution rate will slow as the solution approaches saturation; and(3) the dissolution rate will be constant under conditions far from saturation $(\mathrm{Q} / \mathrm{K} \ll 1)$. All these predictions were in agreement with experimental observations. However, many parameters in Eq. 2 are not known from theory or experiment, so in practice the rate equation needs to be simplified. The model based on a simplified version of Eq.(2), introduced by Grambow[26,56], is the most widely used model for glass corrosion. In Grambow's model, the reaction affinity for glass dissolution is calculated by using only dissolved silica as the value for $\mathrm{Q}$, and $\mathrm{K}$ corresponds to a silica "saturation" value for a particular glass composition at a given temperature and $\mathrm{pH}$. The actual rate equation used is[26,56]:

$$
\mathrm{R}_{\mathrm{m}}=\mathrm{k}_{+}\left(1-\frac{\mathrm{a}_{\mathrm{SiO}_{2}(\mathrm{aq})}}{\mathrm{K}}\right)+\mathrm{R}_{\mathrm{final}}
$$

where $R_{m}$ is the rate of matrix dissolution; $k_{+}$is the rate coefficient; $a_{\mathrm{SiO}_{2}}(\mathrm{aq})$ is the activity of aqueous silica at the reacting surface; $\mathrm{K}$ is the glass saturation silica activity; and $\mathrm{R}_{\text {final }}$ is the final residual rate after silica saturation is achieved. Both $\mathrm{k}_{+}$and $\mathrm{K}$ vary with glass composition, solution composition, and temperature. To date, there is no methodology to extrapolate these parameters to other glasses or test conditions significantly different from those from which $\mathrm{k}_{+}$and $\mathrm{K}$ were regressed.

Under certain open-system test conditions, experimental evidence suggests that the dissolution rate of some glasses is controlled by transport. Grambow [45] hypothesized that the rate-limiting factor was the transport of silica through the surface alteration layers. The transport-limited rate is modelled by a simple diffusion law:

$$
r_{t}=\frac{D}{L}\left(a_{s}-a_{b}\right)+R_{\text {final }}
$$

where $r_{t}$ is the dissolution rate, $\mathrm{D}$ is the diffusion constant, $\mathrm{L}$ is the thickness of the alteration layer, $\left(a_{s}-a_{b}\right)$ is the dissolved silica concentration gradient across the layer from the surface(s) to the bulk solution (b), and $\mathrm{R}_{\text {final }}$ is the "final rate" which is an experimentally estimated 
empirical parameter in agreement with the observed finite rate of glass reaction at "saturation" condition. A rate law is then found by combining Eq.(3) with Eq.(4) to give:

$$
\mathrm{R}_{\mathrm{m}}=\mathrm{k}_{+}\left(\frac{\frac{\mathrm{D}}{\mathrm{L}} \times\left(\mathrm{K}-\mathrm{a}_{\text {bulk }}\right)+\mathrm{R}_{\text {final }}}{\frac{\mathrm{D}}{\mathrm{L}} \times \mathrm{K}+\mathrm{k}_{+}}\right) .
$$

This rate law is implemented into the computer code GLASSOL[45-47]. Input variables are glass and solution composition, time, temperature, glass surface area, solution volume, and flow rate. Rate and stability constants are required and determined by experiments. The model has been rather successful in reproducing certain experiments, but also criticized.

Curti[57] used the Grambow's model to model dissolution of the British MW and pointed out that the model is not yet suitable for safety analysis because(1) the release of radionuclides can only be modelled assuming congruent dissolution; and(2) the magnitude of the final rates of dissolution defining the maximal lifetime of the glass matrix, is still not known with sufficient precision. The Grambow's model does not provide any mechanistic basis for long-term behaviour and the formation of alteration layer. Moreover, experimental results of pristine glass leaching in solution with high concentration of Si showed that the dissolution rate was between the forward rate and residual rate [14]. According to Grambow's model, this is impossible because the chemical affinity is near zero and the alteration rate should be very slow. Based on these experimental observations, Grambow and Muller[13] proposed the GM2001 model in which silicon diffusion in the gel was supplemented with a water diffusion term. Further improvements have been made in the versions GM2003 and GM2004(list possibly not exhaustive, more advanced versions may exist)[19, 58, 59].

Unlike the traditional glass corrosion models, which quantify the release of glass constituents associated with either matrix dissolution or ion exchange, GM2001 considers the penetration of water into glass as the prerequisite for both reactions. The GM2001 model is expressed by a chemical affinity based rate law (still on the base of first order law) along with an equation which describes the water diffusion in glass.

(1) Dissolution rate

$$
r_{\text {glass }}(T)=k_{+}(T)\left(1-\frac{k_{+}(T) F_{\mathrm{S}} \beta L+\emptyset D_{S i}(T) m_{S i, C C B} \rho_{s l n}}{K_{S i O 2}(T) \emptyset D_{S i}(T) \rho_{s l n}+k_{+}(T) F_{S} \gamma_{S i} \beta L} \gamma_{S i}\right),
$$

where $r_{\text {glass }}(T)$ is the glass dissolution rate at temperature $\mathrm{T}\left(\mathrm{kg} \cdot\right.$ glass $\left.\cdot \mathrm{m}^{-2} \cdot \mathrm{s}^{-1}\right) ; \mathrm{k}_{+}(\mathrm{T})$ is the forward rate constant $\left(\mathrm{kg} \cdot\right.$ glass $\left.\cdot \mathrm{m}^{-2} \cdot \mathrm{s}^{-1}\right)$ at temperature $\mathrm{T} ; K_{\mathrm{SiO} 2}(T)(\mathrm{mol})$ is the saturation activity of $\mathrm{Si}$ at temperature $\mathrm{T} ; D_{S i}\left(\mathrm{~m}^{2} \cdot \mathrm{s}^{-1}\right)$ is the pore diffusion coefficient of silicon acid in the layer of thickness $L(\mathrm{~m})$ and porosity $\emptyset$ (dimensionless); $\gamma_{S i}(\mathrm{~kg})$ is the activity coefficient of dissolved silicon; $\beta=S_{r} / S$ (dimensionless) characterizes the ratio of total interfacial surface area $S_{r}$ (including surface roughness )to the cross-sectional surface area $S$ (perpendicular to mass transport direction); $\rho_{s l n}$ is the solution density $\left(\mathrm{kg} \cdot \mathrm{m}^{3}\right) ; \mathrm{m}_{\mathrm{Si}, \mathrm{CCB}}\left(\mathrm{mol} \cdot \mathrm{kg}^{-1}\right)$ is the molality of dissolved $\mathrm{Si}$ in bulk solution; $F_{S}\left(\mathrm{~mol} \cdot \mathrm{kg}^{-1}\right)$ is the factor describing the conversion of reaction rate units from $\mathrm{kg}_{\text {glass }} \mathrm{m}^{-2} \mathrm{~s}^{-1}$ to $\mathrm{mol}_{\mathrm{Si}} \cdot \mathrm{m}^{-2} \mathrm{~s}^{-1}$. This factor is expressed by following equation:

$$
\mathrm{F}_{\mathrm{S}}=\frac{f_{S i}\left(1-f_{r e t}\right)}{M G_{S i O_{2}}}
$$


Where $\mathrm{MG}_{\mathrm{SiO} 2}\left(\mathrm{~kg} \cdot \mathrm{mol}^{-1}\right)$ is the molecular weight of silicon; $f_{S i}$ (dimensionless) is the weight fraction of silicon in pristine glass; $f_{\text {ret }}$ (dimensionless) describes the weight fraction of initially dissolved $\mathrm{Si}$, which became incorporated into secondary alteration productions or sorbed on the glass surface.

Depending on the choice of $L, D_{S i}$ and $\emptyset$, silicon transport can be controlled by either the surface layer or the porous media surrounding the glass.

\section{(2)Water diffusion}

Molecular water is not an insert diffusion species but can react with the glass network. Water penetration is the prerequisite for both matrix dissolution and ion exchange. The GM2003 model provides a more accurate expression for water diffusion and ionexchange[57]. The typical length $\mathrm{L}_{\mathrm{i}}$ in which boron and alkali are depleted is given by:

$$
\mathrm{L}_{\mathrm{i}}(\mathrm{t})=\frac{\varnothing}{\mathrm{K}_{\mathrm{d}, \mathrm{i}}} \int_{0}^{\infty} \mathrm{C}_{\mathrm{H}_{2} \mathrm{O}}(\mathrm{x}, \mathrm{t}) \mathrm{dx}
$$

Where $\varnothing$ is a formal porosity of the glass; $\mathrm{K}_{\mathrm{d}, \mathrm{i}}$ is a proportionality constant $(\mathrm{kg} / \mathrm{litre}$ or $\left.\mathrm{kg} / \mathrm{m}^{3}\right) ; \mathrm{C}_{\mathrm{H} 2 \mathrm{O}}(\mathrm{x}, \mathrm{t})$ is a space and time-dependent concentration of free mobile water molecules in the glass(more details in reference[13]).

Generally, the GM models consider mainly the gel layer and the diffusion layer. Glass dissolution is assumed to be the result of two parallel reactions: (i) water diffusion and(ii) congruent dissolution of(part of) the glass components followed by their diffusion through the gel towards solution. Congruent dissolution of all glass components is assumed to occur at the gel/diffusion layer interface only. From there, the dissolved glass constituents diffuse through the gel towards solution. During transport, some glass components are retained in the gel. Other elements, like boron, are completely released into solution (no retention in the gel).

The model predictions were in good agreement with experimental data[19,57]. To answer Jégou's criticisms[14], Grambow argues that low corrosion affinity is a necessary but not a sufficient condition for the long-term decrease in glass dissolution rates. When a fresh glass exposed to a silica-saturated solution, the affinity effect would be negligible, and the glass alteration rate would be controlled only by diffusion of water in the glass. Thus the glass alteration rate at silica saturation should not depend on the available glass reactive surface area. However, comparing the glass alteration rates measured at various S/V ratios between the moment when the solution is saturated and a given sampling interval(e.g.14 days) shows that the rate clearly depends to a large extent on the S/V ratio[14].

By carefully reviewing and discussing Grambow's models, Gin[60] considered silicate minerals and glasses dissolution rate law based on TST from theoretical viewpoint and found that it is very difficult to determine the content of the affinity function as well as to calculate the activity of the surface species, the first order rate law appears to be a more empirical than theoretical equation. In GM models, the assumption of "chemical affinity" is not fully justifiable for three reasons. Firstly, Si dissolution is assumed to occur at the gel/diffusion layer interface only, and then diffuse through the gel towards solution. So, gel/diffusion layer interface should have the highest Si concentration and the gel/solution interface should have the lowest $\mathrm{Si}$ concentration. As a result, the chemical affinity should be opposite, highest in 
the gel/solution interface but lowest in the gel/diffusion layer interface. If silicon dissolved from the outer surface of the gel, Si should not diffuse but be directly released into solution. So, Si should prefer to dissolve from the outer surface of the gel, and experiments validate this[52]. Secondly, GM models consider the gel as a constant composition boundary, but more resent research found that the gel morphology is changing constantly during glass alteration, and even can close the "kinetic reaction path"[53,54,61,62]. Thirdly, the use of the factor $f_{\text {ret }}$ to describe the weight fraction of initially dissolved Si, which became incorporated into secondary alteration products or sorbed on the glass surface, appears to be an over simplification. These two processes would have very different effect on the corrosion of glass - they both decrease the chemical affinity, but the weight fraction of Si sorbed on the glass surface can result in a densifying reaction and have significant effect on "kinetic reaction path[14,53,54,61,62].

Although a new study[63] has demonstrated that transition state theory can be used in rupture of the glass network bridging bonds, reinforcing the chemical affinity concept, the models based only on chemical affinity do not have any concrete mechanistic basis for the formation and evolution of alteration layer. It is therefore difficult to describe and predict the long-term dissolution of glass by using chemical affinity alone. The morphology evolution of the alteration layer and its passivating properties must be taken into account.

\subsubsection{Diffusion barrier concept and models}

Recent research found that a high repolymerization of the silicate network leading to a self-reorganized submicroporous material, most of this material is passivating, in which only small molecules $(<1 \mathrm{~nm})$ can diffuse[64]. Some authors find that the porous gel may be further subdivided to include a dense zone and a less dense zone with an open porosity[52, 53]. Clearly, these porous layers play very important role during the glass dissolution. Gin[65]found that the formation and evolution of a dense layer during glass dissolution can significantly affect the inter-diffusion process. Even models based on chemical affinity acknowledge this(GLASSOL model[45-47], and GM models[13, 19, 58, 59]).

Based on experimental observations, especially that the initial dissolution rate of a fresh glass exposed to a silica-saturated solution is only slightly lower than that exposed in deionised water, Jégou[14] argues that the driving force behind the alteration of the glasses cannot be defined by the difference from saturation with respect to amorphous silica, and that reaching saturation is not a criterion for the end of alteration. The drop in the dissolution rate observed at a high degree of reaction progress is correlated with the formation of the silica gel that develops at the glass/solution interface. Thermodynamic models based on chemical affinity are ill adapted to describing the formation and development of the silica gel layer over time. Thus, a new concept "dynamic percolation" was introduced, whereas only a dynamic process of hydrolysis and condensation of silicon at the glass/gel interface can account for the formation of the gel layer. The glass alteration rate under silica saturation conditions then highly depends on the silicon recondensation.

In Marcoule model(name of the lab), glass component dissolves congruently from the glass-gel interface, and then diffuses into the solution through the gel layer. Jégou considers the formation of the silica gel when the solubility of the precipitating phase is reached at the 
reaction interphase. Thus the evolution of the silicon concentration in solution $C_{S i}$ and in the glass/gel interface $C_{S i}^{i n t}$ can be described with the following equations :

$$
\begin{gathered}
C_{S i}^{i n t} \approx C_{S i}^{i n t \max }\left[\frac{t}{2 q t_{1}}+1-e^{\frac{-t}{t_{1}}}\right], \\
C_{S i} \approx C_{S i}^{\text {int } \max }\left[\frac{t}{2 q t_{1}}+\frac{1}{2 q}\left(e^{\frac{-t}{t_{1}}}-1\right)\right],
\end{gathered}
$$

where $C_{S i}^{\text {int } \max }$ is the highest silicon concentration at the reaction interface $\left(\mathrm{mg} \cdot \mathrm{l}^{-1}\right)$; $\mathrm{t}$ is the time(s) ; $\mathrm{t}_{1}$ is the diffusion time constant in boundary layer; $q=\delta \mathrm{V} / \mathrm{S}$ (dimensionless), where $\mathrm{S} / \mathrm{V}$ is the ratio of glass surface area to solution volume and $\delta$ is the thickness of the boundary layer(m).

To explain the experimental observation of $\mathrm{Si}$ and $\mathrm{B}$ not being released into solution in a congruent way, Jégou argued that local silicon reorgnization by a dynamic hydrolysis/condensation process can result in the formation of the gel and thus incongruent release of $\mathrm{Si}$ and $\mathrm{B}$.

To reinforce the mechanisms and improve the model, Gin and the other members in the same research team systematically studied the formation conditions[51], morphological evolution during the alteration of glass[52], protective properties and dissolution ability[53] of the gel layer. These works have enhanced our knowledge about the gel in two aspects: (1) link the morphological evolution of gel and the regimes of glass dissolution and(2) demonstrate that after the formation of the gel, the reaction gradually shifts from glass/solution to gel/solution[53].

For the first aspect, during the first stages of alteration, when the glass is altered at the rate close to the maximum rate $\left(r^{0}\right)$, the alteration layer is constituted of a de-alkalinized glass layer with a gel having an open porosity, formed by cross-linking species( $\mathrm{Si}, \mathrm{Al} \ldots)$. Subsequently, the gel becomes denser as the alteration rate decreases[53]. Then the pore size increases and simultaneously a dense and thin zone within the gel are formed when the rate is close to the residual rate.

For the second aspect, Rebiscoul[53] performed an experimental study which consisted in two processes: first glass alteration in order to form gels at different conditions; after that the solution was renewed to investigate the dissolution ability and the protective properties of the gel. Rebiscoul found that after the renewal of the solution, most Si in solution came from the gel, especially those conditions in which the gel was well ripened.

Although many studies provided evidence of the gel as a diffusive barrier[54], models based only on the gel protective properties failed to explain a number of experimental observations. Firstly, under some conditions, layers are not protective[66, 67]. Secondly, according to "dynamic percolation" mechanism and model[14,51], in a steady state, the glass dissolves at its initial rate and recondensation of silanol groups leads to the formation of a gel as a secondary phase. As a consequence, the glass would become transformed into a gel with its initial rate. Experimental observations show that this is not the case. Hence, it is the dissolving phase which is stabilized by recondensation of silanol groups, not a secondary phase. This validates the affinity concept[58]. Thirdly, in some cases, there was no "gel" layer at all, only crystallized secondary precipitation phases, but still the overall dissolution 
decreased as a function of time[27, 68]. Such observations can be better explained by the "chemical affinity" concept.

\subsubsection{Summary of rate drop mechanisms}

As discussed in the previous two sub-sections, both chemical affinity and diffusion barrier have advantages and disadvantages. Neither of them can give successful interpretation of all experimental observations. In fact, the two approaches are not contradictory with each other. There may be consensus on the relative importance or relation between the two mechanisms. At present, more and more researchers realise that it is too simple to regard the control mechanisms of rate drop or residual rate as one single mechanism, the control mechanism can be a combination of the two[12,58, 59]. Sometimes chemical affinity can be dominating[27, 68], sometimes the protective properties of the gel dominating[51-53], and sometimes the rate can be controlled by both mechanisms[59], depending on the glass composition and the leaching conditions. It is essential to find a way to combine the two providing a model with comprehensive application to general glass dissolution.

\subsection{Resumption of alteration(regime $\mathrm{V}$ )}

This stage is observed in some experiments[69], where the rate accelerates, apparently as the result of the formation of new crystalline phases(e.g. zeolites). As with the previous stages, debate over chemical versus transport-dominated rates arises. The increased rates could be due to either local consumption of silica by mineral precipitation reactions or increase in diffusivity of the reactive layer armoring the pristine glass. Fournier[71] gave a very systematic and detailed review on the resumption of nuclear glass alteration. Generally, a resumption of alteration is systematically associated with the precipitation of zeolites and, to a lesser extent, calcium silicate hydrates, and would strongly impact the dissolution kinetics. The mechanism of resumption of alteration can be rather complicated, involving in many parameters such as high $\mathrm{pH}$, temperature, $\mathrm{S} / \mathrm{V}$ ratio, the composition of the glass and also the leaching solutions. When the concentrations of aluminium and silicon in solution high enough at high $\mathrm{pH}$, nucleation and growth of zeolites at the gel/solution interface could occur, this reaction would consume dissolved aluminium and silicon in solution, result in the abstraction of $\mathrm{Al}$ from the protective alteration layer. Thus, the protective alteration layer would lose its passivating properties, and the rate of glass dissolution will be accelerated[48, 71].

\subsection{Summary of kinetic regimes of glass dissolution}

Only the models based on chemical affinity and diffusion barrier are presented in details, as they are the most typical and developed models which focused on the essential mechanisms(chemical affinity or diffusion barrier) controlling the long-term behaviour of the glass dissolution. Other types of models, e.g. based on Free Energy of Hydration, are not considered here, because they are not sufficiently developed to describe long-term corrosion in an operational matter. There are some successful Monte Carlo simulations which based on possibilities and compute calculation[72], such models should also base on concrete mechanisms. The GRAAL(Glass Reactivity with Allowance for the Alteration Layer) model, proposed by Frugier[17,49,50], is quite successful with much stronger mechanistic basis, but 
has the same difficulty to explain experimental observations of decreasing dissolution rate when no gel layer is formed, only crystallized secondary precipitation phases[27,68].

Even after decades of research, there are still many problems need to be addressed in glass corrosion community. Vienna[73] gave a very detailed summarization about current understanding and remaining challenges in modelling long-term degradation of borosilicate nuclear waste glasses. Processes such as Glass/Water Reaction, Reactant and Product Transport, ion Exchange Alteration Product Precipitation and affecting factors such as Glass Composition, Near-Field Materials, Radiation and Decay, Glass Surface Area were carefully summarized. A fundamental understanding of the processes involved in glass corrosion and how environmental conditions will change the rates for each of the concurrent and coupled processes needs to be clear before establishing a robust model. Most papers on dissolution of glasses base the dissolution kinetics on either the affinity function or the protective properties of gel layer. So, when they successfully describe experimental data obtained with given leaching conditions, they may fail to explain other experimental observations(see section 2.3). The combination of these is necessary for capturing simultaneously the effects of chemical affinity, transient diffusive phenomena and the precipitation of secondary minerals. Frugier[17] pointed out some fundamental principle that a combined model should obey: elements supplying PRI constituents favour the rate drop; elements supplying constituents for the crystallized secondary phases can sustain alteration. So a scientific and robust predictive model for long-time glass dissolution must be able to describe the mass balance of the elements distributed among crystallized phases, the amorphous gel and solution at the same time. Each element must therefore be examined to determine its affinity for specific phases, and to describe how it should be taken into account in the model.

\section{Predictive model combining chemical affinity and diffusion barrier}

\subsection{Mechanisms and assumptions}

The model assumptions are illustrated in Fig.2. As described in section 2.3, during alteration, an amorphous, porous, hydrated phase enriched in Si and other network-forming elements was formed between the pristine glass and solution. This phase has different names in different papers, such as 'gel' [14, 40, 41], PRI[17, 49, 50] or hydrated glass[13]. To avoid confusion, we refer to the reorganized phase which has protective properties as the interfacial diffusion barrier(IDB). Frugier[17,49,50] referred this layer as passivating reaction interface(PRI), and from the description of PRI, it was in fact no difference with "hydrated glass". In some cases, the layer created by regime I and II (depleted in B and alkalis) which was defined as PRI by Frugier does have protective properties, but in other conditions, it may not[74,75]. In this paper, the IDB, which does have protective properties and limits the diffusion of water and mobile elements (especially B and alkalis), is in fact the denser zone within the alteration layer[52, 53]. And we assume that IDB only forms in certain conditions, such as obtaining a threshold concentration of $\mathrm{Si}$ in solution[51]. The other zones(diffusion zone, hydrated zone, hydrated zone depleted in network-forming elements and secondary precipitation zone) are also described together with IDB, but were assumed had much less protective properties compared to IDB, see Fig.2. 


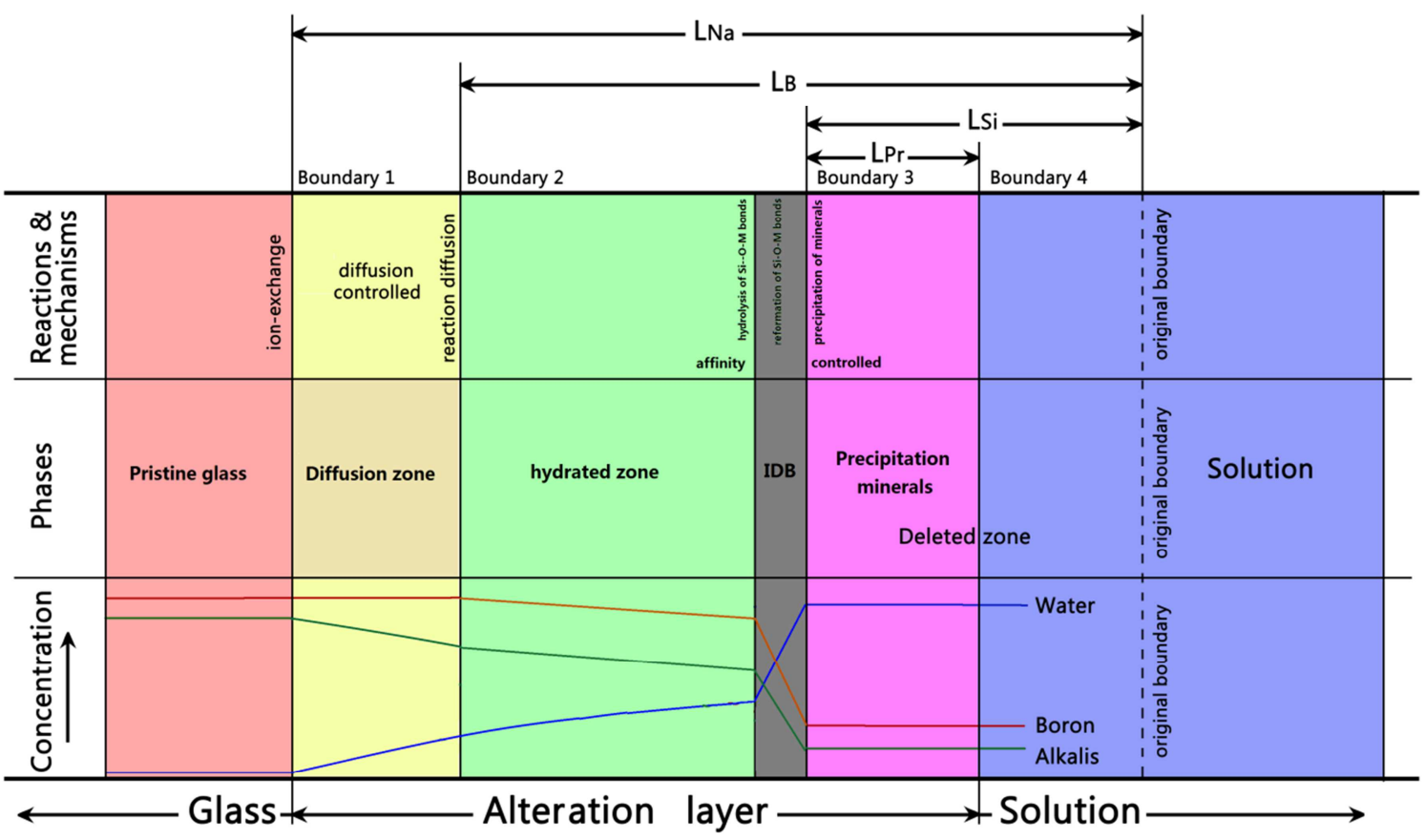

Fig.2. Simplified presentation of assumptions and mechanisms taken account into this model

The model contains three main points:

(1) Water diffusion controls the release of glass modifier, like alkalis and B, i.e. water diffusion controls the rate of glass transformation into gel - the moving speeds of boundaries 1 and 2, determine $L_{N a}$ and $L_{B}$, see Fig.2;

As the water penetrates, the ion-exchange reaction between alkalis and protons, and hydrolysis of B can occur rapidly(the rate of ion-exchange is slightly faster than hydrolysis of $\mathrm{B}$ as observed in experiment).This means that wherever water penetrates, alkalis and $\mathrm{B}$ are released into solution. The fact that water diffusion is the rate limiting process has been validated both by theory and experimental observation(see section 2.1), and also further verified by modern experimental methods[20]: At the beginning of the alteration in water( $\mathrm{pH}$ 3 ), the altered surface layer is constituted of a dealkalized zone. Upon alteration progress, the water diffuses inside the layer and hydrolyzes the $\mathrm{Si}-\mathrm{O}-\mathrm{B}$ bonds. Clearly, water diffusion is not limited in the first steps, but occurs during the whole alteration of glasses[19, 20].

(2) Chemical affinity controls the distribution of Si between solution, gel and secondary precipitation phases - the moving speed of boundaries 3 and 4, determine $L_{S i}$ and $L_{p r}$, see Fig. 2 ;

$\mathrm{Si}$ in solution is due to the hydrolysis of Si-O-M bonds, which is controlled by chemical affinity discussed in Section 2.2 and further verified by modern experimental methods[63]. The mechanism of the formation of IDB is still an argument. Some authors argue that the IDB is formed by recondensation reaction of dissolved species(especially $\mathrm{Si}$ )[51], but some argue it is formed by in- situ reorganization(named as 'gel' )[41]. In any case, IDB is formed by an elemental reaction, controlled by chemical affinity, thus dependent on the $\mathrm{Si}$ concentration in solution and/or the density of silanol groups in the gel. The secondary precipitation phases depend both on the glass composition and the available ions in solution - 
glass leaching in sea water is easy to form minerals rich in $\mathrm{K}, \mathrm{Na}, \mathrm{Mg}[8,11]$ and leaching in solution with high $\mathrm{Ca}$ concentration is easy to form Ca minerals[16]. Hence, precipitation can be considered as controlled by the available Si concentration in a given system with constant concentrations of other available ions. The Si concentration will increase until saturation is achieved, but at the same time, if the concentration became higher than the threshold to form IDB or secondary phases, it would be consumed by the formation of IDB or secondary precipitation phases. The balance is maintained by chemical affinity, and Si is distributed among these three phases.

(3) Si condensation reaction within the amorphous layer has a significant effect on the morphologic evolution of the amorphous layer and may form an IDB - a diffusion barrier between solution and pristine glass, leading to a significant rate drop for alkalis and B.

Not all gels have protective properties; the IDB which does have protective properties is a condense zone within the amorphous layer, but it cannot be formed in all conditions (see section 2.3.2). If IDB is formed, its properties will depend on its morphology, such as thickness, and it will have a maximum protective effect according to Gin[51] and Rebiscoul[52,53]. The morphological evolution process of IDB is a dynamic reaction involving both the pristine glass and the solution. Concerning the pristine glass, the water diffusion and release of glass modifiers(B, alkalis) offers a base for the IDB formation, and the formation and evolution of IDB protects the pristine glass by inhibiting the mass exchange between glass and the solution. Concerning the solution, if it is not saturated, the gel will keep dissolving but with a decreasing rate as the concentration builds, and when the concentration of Si becomes higher than a threshold, the condensation reaction will occur and IDB will be formed and developing.

Based on these mechanisms, the dissolution of glass can be described as follow:

(1) Regime I interdiffusion: At the beginning of reaction, pristine glass contacts with water, the reactions of ion-exchange, hydrolysis of $\mathrm{B}$ and Si-O-M bonds all start at their highest but reaction specific rates. As the water penetration is prerequisite for both ionexchange and hydrolysis of $\mathrm{B}$, water diffusion rate sets a limit for the two reactions rates. The slightly discrepancy between ion-exchange and hydrolysis of $\mathrm{B}$ rates result in a diffusion zone as described by Rébiscoul[20] and shown in Fig.2. (2)Regime II hydrolysis process: The hydrolysis of Si-O-M, especially of silicon, determines an initial glass dissolution rate. The difference between release rate of glass modifier and Si leads to the creation of an amorphous layer at the glass/solution interface regardless of the alteration conditions. This layer, called gel, has no or limited protective properties but relatively high solubility. (3) Regime III rate drop: As the concentration of $\mathrm{Si}$ in solution increases, the chemical affinity of Si becomes smaller and smaller, the rate of $\mathrm{Si}$ release into solution decreases accordingly. If the $\mathrm{Si}$ concentration is high enough, condensation reaction within the amorphous layer formed in regime II may form IDB or precipitation minerals, If only the IDB formed, the release rate of B and alkalis decreases accordingly. (4) Regime IV residual rate: the distribution of Si among phases reaches steady state and the concentration of $\mathrm{Si}$ in solution is maintained at approximately constant value. The IDB formed in regime III also develops so that its protective properties reach maximum. This leads to approximately constant diffusion coefficient of B and alkalis, much slower than regime I because of the IDB diffusion barrier. 
(5) regime $\mathrm{V}$ Resumption of alteration: If special secondary precipitation minerals formed (namely zeolites and calcium silicate hydrates), the $\mathrm{Al}$ and $\mathrm{Si}$ in solution is consumed and abstracted from IDB to support the precipitation of such minerals, the IDB protection would be lost, leading to resumption of nuclear glass alteration.

It is emphasised that the presented mechanisms are quite different from Marcoule models[14, 53] and GM models[13, 19, 58, 59]. All these models assume congruent release of glass components from the gel/glass interface, incongruent accumulation of these components in solution was caused by different chemical behaviour (such as diffusion behaviour or chemical affinity changing). Here, we propose that different elements' releases are controlled by different mechanisms; there are no intrinsic relations to release them concurrently. In addition, this model emphasizes on $\mathrm{Na} 、 \mathrm{~B} 、 \mathrm{Si}$ as they were the most familiar elements which can reveal the dissolution rate of borosilicate glass. Ledieu[61], Devreux[62] investigated leaching behaviour of borosilicate glasses. Their result showed that the leached fractions $\operatorname{LF}(\mathrm{B})$ and $\mathrm{LF}(\mathrm{Na})$ are low and nearly equal to $\mathrm{LF}(\mathrm{Si})$ for the glasses with boron (and sodium) oxide content less than 15 mol\%. This is the mark of an approximately concurrent dissolution for these glasses. When the boron (and sodium) oxide content increases from $15 \mathrm{~mol} \%$ to $20 \mathrm{~mol} \%$, there is a sharp increase of $\operatorname{LF}(\mathrm{B})$ and $\operatorname{LF}(\mathrm{Na})$ compared to $\mathrm{LF}(\mathrm{Si})$. The $\mathrm{LF}(\mathrm{B})$ and $\mathrm{LF}(\mathrm{Na})$ saturate to unity, which means that all the soluble cations have been removed, whereas the dissolved fraction of silicon remains lower. Ledieu studies validate our proposal in two ways:(1) $\mathrm{B}$ and $\mathrm{Na}$ are released almost concurrently because the two elements are controlled by the same mechanism-water diffusion; slight differences are due to their different kinetics studied by Geneste[25]; and (2) the significant difference between $\mathrm{B}$ and $\mathrm{Si}$ release suggests that they are controlled by different mechanisms. Bunker[21] points out that different bond types in glass are hydrolysed via different mechanisms and at different rates. If a glass contains voids of sufficient size, water diffusion is relatively rapid, otherwise, the only way for water to penetrate into the structure is by hydrolysis of its bonds. Considering Geneste's work and Bunker's conclusion, provides a strong support for the proposed mechanisms.

\subsection{Model equations}

The model contains six equations:

(1) An equation group describing water diffusion controlled ion-exchange

(2) An equation group describing water diffusion controlled reactive diffusion

(3) An equation describing thermodynamic equilibrium(chemical affinity) controlled glass (at low alteration progress) or IDB(at high alteration progress) dissolution

(4) An equation describing thermodynamic equilibrium(chemical affinity) controlled IDB formation and developing

(5) An equation describing thermodynamic equilibrium(chemical affinity) controlled formation and accumulation of secondary precipitation phases

(6) An equations describing the silicon mass balance 
This model is a strongly mechanistic based model; each equation has a concrete mechanism base(except silicon mass balance equation). All parameters are correspondingly selected.

3.2.1 Model parameters and physical meanings

$L_{\mathrm{Na}}(t)$ : equivalent leached thickness of $\mathrm{Na}(\mathrm{m})$ at time $t(\mathrm{~s})$;

$L_{B}(t)$ : equivalent leached thickness of $\mathrm{B}(\mathrm{m})$ at time $t$;

$L_{S i}(t)$ : equivalent leached thickness of $\mathrm{Si}(\mathrm{m})$ at time $t$;

$L_{I D B}(t)$ :equivalent thickness of $\operatorname{IDB}(\mathrm{m})$ at time $t$ (condense zone within gel);

$L_{p r}(t)$ : equivalent thickness of secondary precipitation minerals $(\mathrm{m})$ at time $t$;

$D_{\text {eff,Na }}$ : effective water diffusion coefficient of $\mathrm{Na}^{+}\left(\mathrm{m}^{2} \cdot \mathrm{s}^{-1}\right)$, which may change as a function of time due to formation and development of IDB;

$D_{e f f, B}$ : effective water diffusion coefficient of $\mathrm{B}\left(\mathrm{m}^{2} \cdot \mathrm{s}^{-1}\right)$, also may change as a function of time due to formation and development of IDB;

$\mathrm{D}_{0}$ : water diffusion constant (initial, with no diffusion barrier) in glass of $\mathrm{Na}^{+}\left(\mathrm{m}^{2} / \mathrm{s}\right)$;

$\mathrm{D}_{0}{ }^{\prime}$ : water diffusion constant in glass of $\mathrm{B}\left(\mathrm{m}^{2} / \mathrm{s}\right)$;

$\mathrm{D}^{\prime}$ : effective coefficient of IDB for water diffusion $\left(\mathrm{m}^{-1}\right)$;

A: the pre-exponential factor of water diffusion $\left(\mathrm{m}^{2} \cdot \mathrm{s}^{-1}\right)$;

$\mathrm{E}_{\mathrm{a}, \mathrm{Na}}$ : apparent activation energy of $\mathrm{Na}^{+}$release, including water diffusion and ion exchange; the energy required to release $1 \mathrm{~mol}$ of $\mathrm{Na}^{+}$into solution $\left(\mathrm{kJ}^{\mathrm{mol}}{ }^{-1}\right)$;

$\mathrm{E}_{\mathrm{a}, \mathrm{B}}$ :apparent activation energy of $\mathrm{B}$ release, including water diffusion and $\mathrm{B}$ hydrolysis; the energy required to release $1 \mathrm{~mol}$ of $\mathrm{B}$ into solution $\left(\mathrm{kJ} . \mathrm{mol}^{-1}\right)$;

$\mathrm{m}$ : chemical stoichiometric numbers of $\mathrm{H}^{+}$water diffusion(dimensionless);

$r^{0}$ : initial dissolution rate of glass or porous $\mathrm{Si}$ phase $(\mathrm{m} / \mathrm{s})($ this parameters will be discussed together with $\mathrm{r}^{\mathrm{IDB}}, \mathrm{C}_{\mathrm{Si}}^{*}$, glass, $\mathrm{C}_{\mathrm{Si}}^{*}$ and $\mathrm{C}_{\mathrm{Si}}^{*}$, IDB in section 4.2.2);

$\mathrm{k}^{+}$: the forward rate constant $(\mathrm{m} / \mathrm{s})$;

$\mathrm{n}$ : variation, chemical stoichiometric numbers of $\mathrm{H}^{+}$for $\mathrm{Si}$ releasing(dimensionless);

$\mathrm{r}^{\mathrm{IDB}}$ : initial dissolution rate constant of $\operatorname{IDB}(\mathrm{m} / \mathrm{s})$;

$\mathrm{k}_{\mathrm{b}}$ : kinetic constant of condensation reaction which result in the formation of $\operatorname{IDB}(\mathrm{m} / \mathrm{s})$;

$\mathrm{k}^{\prime}$ : precipitation rate parameter $(\mathrm{m} / \mathrm{s})$;

$C_{S i}(t)$ : Si concentration in solution $(\mathrm{g} / \mathrm{L})$ at time $\mathrm{t}$;

$\mathrm{C}_{\mathrm{Si}}^{*}$ : saturation concentration of $\mathrm{Si}$; depending on leaching conditions this can be equal to $\mathrm{C}^{*} \mathrm{Si, \text {glass }}$ or $\mathrm{C}_{\mathrm{Si}, \mathrm{IDB}}^{*}$ (see section 4.2 .2 );

$\mathrm{C}^{*}$ Si,glass: $\mathrm{Si}$ saturation concentration with respect to pristine glass or amorphous silica $\operatorname{phases}(\mathrm{g} / \mathrm{L})$;

$\mathrm{C}_{\mathrm{Si}, \mathrm{IDB}}^{*}$ : Si saturation concentration with respect to $\mathrm{IDB}(\mathrm{g} / \mathrm{L})$;

$\mathrm{C}^{*}{ }_{\mathrm{Si} \text {,set }}$ : threshold concentration of Si to form $\operatorname{IDB}(\mathrm{g} / \mathrm{L})$;

$\mathrm{C}_{\mathrm{Si}}^{*}$, pr: threshold concentration of $\mathrm{Si}$ to form secondary precipitation phases; the solubility of relative precipitation phases $(\mathrm{g} / \mathrm{L})$;

$\mathrm{V}$ : the reactor volume $(\mathrm{L})$;

$\mathrm{S}$ : the reaction surface $\left(\mathrm{m}^{2}\right)$;

$x_{S i}^{g l a s s}, x_{S i}^{I D B}, x_{S i}^{p r}$ : Silicon mass fraction in glass, IDB and precipitation phase respectively $(\mathrm{g} / \mathrm{g})$; 
$\rho^{\text {glass }}, \rho^{I D B}, \rho^{p r}:$ Density of glass, IDB and precipitation phase respectively $\left(\mathrm{g} / \mathrm{cm}^{3}\right) .3 .2 .2$ Model equations

Kinetics of water diffusion and ion exchange is described by

$$
\begin{gathered}
\frac{\mathrm{dL}_{\mathrm{Na}}(\mathrm{t})}{\mathrm{dt}}=\frac{2 \mathrm{D}_{\mathrm{eff}, \mathrm{Na}}}{\pi\left(\mathrm{L}_{\mathrm{Na}}(\mathrm{t})-\mathrm{L}_{\mathrm{Si}}(\mathrm{t})\right)}, \\
D_{e f f, N a}(t)=\frac{D_{0}}{D^{\prime} L_{I D B}(t)+1}=\frac{\mathrm{A} \times\left[\mathrm{H}^{+}\right]^{\mathrm{m}} \times \exp \left(-\frac{\mathrm{E}_{\mathrm{a}, \mathrm{Na}}}{\mathrm{RT}}\right)}{D^{\prime} L_{I D B}(t)+1} .
\end{gathered}
$$

The term $D^{\prime} L_{I D B}(t)+1$ denotes the effect of IDB formation and evolution on the diffusion of water. This equation implies that the corrosion front advance rates can be a function of the effective diffusivity of water, diffusion distance and time. It describes the moving speed of boundary 1, shown in Fig.2; providing the equivalent leached thickness of $\mathrm{Na}, \mathrm{L}_{\mathrm{Na}}$.

Kinetics of water diffusion and hydrolysis of B is given by

$$
\begin{gathered}
\frac{\mathrm{d}_{\mathrm{B}}(\mathrm{t})}{\mathrm{dt}}=\frac{2 \mathrm{D}_{\text {eff, } \mathrm{B}}}{\pi\left(\mathrm{L}_{\mathrm{B}}(\mathrm{t})-\mathrm{L}_{\mathrm{Si}}(\mathrm{t})\right)}, \\
D_{e f f, B}(t)=\frac{D_{0}^{\prime}}{D^{\prime} L_{I D B}+1}=\frac{\mathrm{A} \times\left[\mathrm{H}^{+}\right]^{\mathrm{m}} \times \exp \left(-\frac{\mathrm{E}_{\mathrm{a}, \mathrm{B}}}{\mathrm{RT}}\right)}{D^{\prime} L_{I D B}+1} .
\end{gathered}
$$

This equation describes the moving speed of boundary 2, providing the equivalent leached thickness of $B, L_{B}$. The slight discrepancy of the activity energy between the ionexchange and hydrolysis of B leads to the thickness of the inter-diffusion zone, as shown in Fig.2. The similarity between Eqns.(11) and Eqns.(12) is because both reactions are controlled by water diffusion. As the retention in alteration layers can be negligible, $\mathrm{B}$ is more suitable than $\mathrm{Na}$ as the glass alteration tracer[69], especially in long-term conditions.

Kinetics of glass or IDB dissolution is described by

$$
\begin{gathered}
\frac{\mathrm{dL}_{\mathrm{Si}}(\mathrm{t})}{\mathrm{dt}}=\mathrm{r}^{0}\left(1-\frac{\mathrm{C}_{\mathrm{Si}}(\mathrm{t})}{C_{S i}^{*}}\right) . \\
\mathrm{r}^{0}=\mathrm{k}^{+}\left[\mathrm{H}^{+}\right]^{\mathrm{n}} \exp \left(-\frac{\mathrm{E}_{\mathrm{a}, \mathrm{Si}}}{\mathrm{RT}}\right)
\end{gathered}
$$

This equation describes the moving speed of boundary 3, providing the equivalent leached thickness of $\mathrm{Si}, L_{S i}$. Note that here, $\mathrm{n}$ is not a constant, but a variation. $\mathrm{pH}$ plays a very complicated but important role in glass dissolution. The hydrolysis process has been observed to accelerate in both acid and basic conditions, with a lowest rate in neutral 
environment [26, 27,70]. Equation (13b) captures both the temperature and $\mathrm{pH}$ dependence of the initial rate and therefore $\mathrm{k}^{+}, \mathrm{E}_{\mathrm{a}, \mathrm{Si}}$ and potentially $\mathrm{n}$ are specific to a particular glass. These parameters can be obtained by experimental date. Thus, initial dissolution rate of glass or porous $\mathrm{Si}$ phase $\mathrm{r}^{0}$ mainly depended on $\mathrm{pH}$ and temperature. In this equation, the parameters $\mathrm{r}^{0}$ and $\mathrm{C}_{\mathrm{Si}}^{*}$ are used. When contacted with water, pristine glass or the porous Si phase formed in the beginning of alteration(depleted in alkalis and B but not yet reorganized) has relatively larger solubility compared to IDB due to lower stability. This is the reason for the use of $\mathrm{r}^{0}$. At high alteration, when the gel is reorganized, IDB has already formed and developed, Si is released from the outer face of IDB(highest chemical affinity and no need of diffusion as discussed in section 2.3.1) and equilibrium is established between IDB and solution. This equation will be further discussed in section 4.2.2.

Kinetics of IDB formation is described by

$$
\frac{d L_{I D B}(t)}{d t}=k_{b} x_{S i}^{g l a s s}\left(\frac{c_{S i}(t)}{c_{S i, s e t}^{*}}-1\right)
$$

In this equation, the condensation reaction to form IDB is described, using a parameter $\mathrm{C}^{*} \mathrm{Si}$, set, as the threshold concentration of $\mathrm{Si}$ in the solution at which the condensation reaction occurs. If the IDB forms by in-situ condensation of silanol groups, the formation rate should be directly proportional to the fraction of $\mathrm{Si}$ in glass $x_{S i}^{\text {glass }}$, as this fraction controls the density of in-situ silanol groups. If the IDB forms by recondensation reaction of dissolved species, the formation rate should be directly proportional to the Si concentration in solution. In this model, the mechanisms of IDB formation are considered to be a combination of the two, with an adjustable constant parameter $\mathrm{k}_{\mathrm{b}}$. The threshold $\mathrm{C}_{\mathrm{Si}}^{*}$, set is used to control the IDB formation to cover for cases when glasses do not form IDB during leaching. Specifically, when the concentration of $\mathrm{Si}$ in solution is less than the threshold value $\mathrm{C}_{\mathrm{Si}}^{*}$, set, there is no IDB formed, no diffusion barrier built between pristine glass and solution, water can penetrate into the glass with a diffusion constant just as the inter-diffusion regime. The value of $\mathrm{C}^{*} \mathrm{Si}$, set varies for different types of glasses.

Secondary phase precipitation is given by

$$
\frac{\mathrm{dL}_{\mathrm{pr}}(\mathrm{t})}{\mathrm{dt}}=\mathrm{k}^{\prime}\left(\frac{\mathrm{C}_{\mathrm{Si}(\mathrm{t})}}{\mathrm{C}_{\mathrm{Si}, \mathrm{pr}}^{*}}-1\right)
$$

In the model, secondary phase precipitation concerns only silicon; it is assumed that only a single phase with a density $\rho$ ' is formed. When other available ions are fixed in a given system, the formation rate of this single phase is determined by only Si concentration with a threshold of $\mathrm{C}^{*} \mathrm{Si}$, pr and a kinetic parameter $\mathrm{k}$. 
Si balance is given by

$$
\mathrm{V} \frac{\mathrm{dC}_{\mathrm{Si}}(\mathrm{t})}{\mathrm{dt}}=\rho^{\text {glass }} \mathrm{S} x_{S i}^{\text {glass }} \frac{\mathrm{dL}_{\mathrm{Si}}(\mathrm{t})}{\mathrm{dt}}-\rho^{I D B} S x_{S i}^{I D B} \frac{\mathrm{dL}_{\mathrm{IDB}}(\mathrm{t})}{\mathrm{dt}}-\rho^{p r} S x_{S i}^{p r} \frac{\mathrm{dL}_{\mathrm{pr}}(\mathrm{t})}{\mathrm{dt}},
$$

or

$$
\frac{\mathrm{dC}_{\mathrm{Si}}(\mathrm{t})}{\mathrm{dt}}=\frac{\rho^{\text {glass }} \mathrm{Sx}_{\mathrm{Si}}^{\text {glass }} \mathrm{r}^{0}}{\mathrm{~V}}\left(1-\frac{\mathrm{C}_{\mathrm{Si}}(\mathrm{t})}{\mathrm{C}_{\mathrm{Si}}^{*}}\right)-\frac{\rho^{\mathrm{IDB}} \mathrm{Sx}_{\mathrm{Si}}^{\mathrm{IDB}} \mathrm{k}_{\mathrm{b}}}{\mathrm{V}}\left(\frac{\mathrm{C}_{\mathrm{Si}}(\mathrm{t})}{\mathrm{C}_{\mathrm{S}, \mathrm{set}}^{*}}-1\right)-\frac{\rho^{\mathrm{pr}} \mathrm{Sx}_{\mathrm{Si}}^{\mathrm{pr}} \mathrm{k}^{\prime}}{\mathrm{V}}\left(\frac{\mathrm{C}_{\mathrm{Si}}(\mathrm{t})}{\mathrm{C}_{\mathrm{Si}, \mathrm{pr}}^{*}}-1\right),
$$

This can be simplified, by defining $X=\rho^{\text {glass }} x_{S i}^{\text {glass }} r^{0}, \mathrm{Y}=\rho^{I D B} x_{S i}^{I D B} k_{b}, Z=\rho^{p r} x_{S i}^{p r} k^{\prime}$, which characterise glass, IDB and the secondary mineral phases, to the following:

$$
\frac{\mathrm{d} C_{S i}(t)}{d t}=\frac{S}{V}(X+Y+Z)-\frac{S}{V}\left(\frac{X}{C_{S i}^{*}}+\frac{Y}{C_{S i, s e t}^{*}}+\frac{Z}{C_{S i, p r}^{*}}\right) C_{S i}(t)
$$

This equation distributes $\mathrm{Si}$ to solution, IDB and precipitation phases, all processes controlled by chemical affinity. When $d C_{S i}(t)=0$, the system is in steady-state macroscopically/observably, i.e. the concentration of $\mathrm{Si}$ in solution is constant, but this does not mean the glass dissolution ceased. Different Si distributions would lead to different behaviour: (1)Si increase in the solution would decreases the chemical affinity, thus inhibiting further hydrolysis of Si-O-M bonds of hydrated glass or IDB; (2) Si increase in IDB can be more complicated - on one hand, it can decrease the chemical affinity, thus accelerating the hydrolysis of Si-O-M bonds, on the other hand, it can build a diffusion barrier and inhibit the release of $\mathrm{B}$ and alkalis, and the condensation reaction also makes IDB itself more stable; (3) Si increase in precipitation phases would decrease the chemical affinity, thus accelerating the hydrolysis of Si-O-M bonds.

\section{Discussion of proposed model}

\subsection{Solution of model equations}

Proposed is a solution of the model equations using a numerical method, e.g. time and space centred forward algorithm, which was the same as GM models[13]. Given below are the equations with boundary conditions solved numerically.

(1) Evolution of Si concentration in solution

$$
C_{S i}(t+\Delta t)=C_{S i}(t)+d C_{S i}(t)=\frac{S \Delta t}{V}(X+Y+Z)-\frac{S \Delta t}{V}\left(\frac{X}{C_{S i}^{*}}+\frac{Y}{C_{S i, S e t}^{*}}+\frac{Z}{C_{S i, p r}^{*}}\right) C_{S i}(t),
$$

where $\mathrm{dC}_{\mathrm{Si}}(\mathrm{t})$ defined as the evalution rate of $\mathrm{Si}$ concentration in solution at time $\mathrm{t}$. Boundary conditions: $\mathrm{C}_{\mathrm{Si}}(0)=0$ if $\mathrm{C}_{\mathrm{Si}}(\mathrm{t})<\mathrm{C}^{*}{ }_{\mathrm{Si} \text {,set }}, Y=0$; if $\mathrm{C}_{\mathrm{Si}}(\mathrm{t})<\mathrm{C}^{*}{ }_{\mathrm{Si}, \mathrm{pr}}, Z=0$. 
(2) Evolution of IDB

$$
L_{I D B}(t+\Delta t)=L_{I D B}(t)+k_{b} x_{S i}^{g l a s s}\left(\frac{C_{S i}(t)}{c_{S i, s e t}^{*}}-1\right) \Delta t,
$$

Boundary conditions: if $\mathrm{C}_{\mathrm{Si}}(\mathrm{t})<\mathrm{C}_{\mathrm{Si} \text {, set }}^{*} L_{I D B}(t)=0$.

(3) Evolution of equivalent leached thickness of $\mathrm{Na}(\mathrm{m})$

$$
L_{N a}(t+\Delta t)=L_{N a}(t)+\frac{2 D_{0}}{\pi\left(L_{N a}(t)-L_{S i}(t)\right)\left(D^{\prime} L_{I D B}(t)+1\right)} \times \Delta t,
$$

(4) Evolution of equivalent leached thickness of $\mathrm{B}(\mathrm{m})$

$$
L_{B}(t+\Delta t)=L_{B}(t)+\frac{2 D_{0}^{\prime}}{\pi\left(L_{B}(t)-L_{S i}(t)\right)\left(D^{\prime} L_{I D B}(t)+1\right)} \times \Delta t,
$$

(5) Evolution of equivalent leached thickness of $\mathrm{Si}(\mathrm{m})$

$$
L_{S i}(t+\Delta t)=L_{S i}(t)+r^{0}\left(1-\frac{C_{S i}(t)}{C_{S i}^{*}}\right) \Delta t
$$

$\mathrm{Si}$ concentration is the key parameter of the numerical scheme; the solution for $\mathrm{Si}$ concentration at each time step is used to calculate the evolution of $L_{I D B}, L_{N a}, L_{B}$ and $L_{S i}$. In this numerical scheme, the step $\operatorname{size}(\Delta t)$ is selected sufficiently small at regime I, II and III as not to be of influence on the results, at regime $\mathrm{IV}, \Delta \mathrm{t}$ can be selected relatively bigger as its influence on the results would be smaller.

The quantitative implementation of the model needs to give every model parameter suitable value. These parameters can be obtained by(1) chemical analysis and calculating(like $\mathrm{r}^{0}, \mathrm{D}_{0}, \mathrm{D}_{0}^{\prime}$, etc.); and(2) solid phase properties determination(using modern experimental techniques such as SEM, TEM, in situ X-ray reflectometry etc.) and calculation, especially relating to the parameters concerning IDB (like $D^{\prime}, r^{I D B}, \rho^{I D B}, x_{S i}^{I D B}, k_{b}, C_{S i, s e t}^{*}$ ); and(3) geochemical models(such as $\mathrm{EQ} 3 / 6)$, relating to the properties concerning secondary minerals(like $\left.\mathrm{k}^{\prime}, \rho^{\mathrm{pr}}, \mathrm{x}_{\mathrm{Si}}^{\mathrm{pr}}, \mathrm{C}_{\mathrm{Si}}^{*}\right)$. After getting the values of model parameters, the relation between $\mathrm{L}_{\mathrm{Na}}, \mathrm{L}_{\mathrm{B}}, \mathrm{L}_{\mathrm{Si}}, \mathrm{L}_{\mathrm{IDB}}, \mathrm{L}_{\mathrm{pr}}$ and time can be quantitatively established and extrapolated to the time where laboratory experiment can't reach. 


\subsection{Model interpretation of published experimental observations}

Although the model description is based on static leaching system, it can be applied to dynamic leaching systems. If $\Omega(\mathrm{L} / \mathrm{s})$ is the water flow rate, a flow term can be added in Eq.16. The contribution of this flow term on the change of Si concentration in solution can be described as $\mathrm{C}_{\mathrm{Si}}(\mathrm{t}) \Omega / \mathrm{V}$. In such case Eq.(17) should be changed accordingly.

\subsubsection{Four main different glass dissolution behaviours}

Based on Eq.16, the model divides glass dissolution into four categories, illustrated in Fig.3.

Category 1: $\mathrm{C}_{\mathrm{Si}}^{*}<\mathrm{C}_{\mathrm{Si} \text {,set }}^{*}<\mathrm{C}_{\mathrm{Si} \text {,pr }}^{*}$. This represents a case when both IDB and precipitation phases are not formed even when saturation (with amorphous silica or silica polymorph formed during alteration) conditions are reached. Under this condition, the evolution of $\mathrm{Si}$ concentration in solution will follow chemical affinity controlled first order rate law. The concentration of $\mathrm{Si}$ in solution will increase with decreasing rate approaching zero. $\mathrm{B}$ and $\mathrm{Na}$, however, are controlled by water diffusion with a constant diffusion coefficient. The gel formed by the release discrepancy between glass modifiers $(\mathrm{B}, \mathrm{Na})$ and $\mathrm{Si}$ has no protective properties, thus it cannot inhibit water diffusion. Glass would transform into gel as the result of water diffusion and release of glass modifiers. This condition has been studied and described by Cailleteau[74, 75] for glass samples containing $8 \mathrm{~mol} \% \mathrm{ZrO}_{2}$. According to the experimental date of literature[74,75], the releasing of $\mathrm{B}$ and $\mathrm{Na}$ from glass containing $8 \mathrm{~mol} \%$ $\mathrm{ZrO}_{2}$ almost had a linear relationship with $\mathrm{t}^{1 / 2}$, which denoted diffusion controlled mechanism, and the soluble cations were free to diffuse toward solution across the gel layers in this condition. Neither GM models nor diffusion barrier models can explain these observations clearly. According to GM2001[13], at silicon saturation the release rate of the soluble elements $(\mathrm{B}, \mathrm{Na}$ ) should be slowed down by several orders of magnitude, unless dissolved $\mathrm{Si}$ is reincorporated into solid products. But in this condition, no solid products, and also no slowing down of soluble elements $(\mathrm{B}, \mathrm{Na})$ even at $\mathrm{Si}$ saturation conditions is experimentally observed. According to Marcoule model[14], the glass does become transformed into a gel but not with its initial rate, and the release rates are quite different for different elements, not consistent with experiments.

Category 2: $\mathrm{C}_{\mathrm{Si}, \mathrm{pr}}^{*}<\mathrm{C}_{\mathrm{Si}}{ }_{\mathrm{Si}}<\mathrm{C}_{\mathrm{Si} \text {,set }}^{*}$ This represents a case where the Si concentration in solution reaches the threshold value of $\mathrm{C}_{\mathrm{Si}}^{*}$, pr, leading to precipitation of minerals, but without formation of IDB. These conditions usually occur on glass samples that contain no or low fraction of B, like nuclear explosive melt glasses[27]. The glass is transformed into secondary precipitate minerals in this case; the rate is decreasing to reach a relatively constant value. This case cannot be explained by diffusion barrier models but can be described by Grambow's law, using an empirical parameter $r_{\text {final }}$, arguing that residual rate is controlled by secondary precipitation phases. According to this model, the term $r_{\text {final }}$, can be explained as controlled by both glass dissolution and the precipitation of minerals, and $\mathrm{Si}$ is distributed between solid alteration products and solution by chemical affinity. When $d C_{S i}(t)=0$, the reaction reaches a dynamic equilibrium: the rate at which $\mathrm{Si}$ is released from pristine glass into solution equals the rate of $\mathrm{Si}$ precipitation from solution into secondary minerals. The result is that the glass transforms into solid products at a constant rate, described by $r_{\text {final }}$ in 
Grambow's law. The concentration of $\mathrm{Si}$ in steady-state and the final rate, $\mathrm{r}_{\text {final }}$, in Grambow's law obtained by fitting experimental date, can be calculated by Eq.(16), given every characteristic parameter is known. Notably, the concentration of $\mathrm{Si}$ at dynamic equilibrium is not the saturate concentration, because chemical affinity of glass dissolution is above zero so that it can support the precipitation reaction. So, the equilibrium concentration must be smaller than saturation concentration, which is different from Grambow's model.

Category 3: $\mathrm{C}^{*}{ }_{\mathrm{Si} \text {,set }}<\mathrm{C}^{*}{ }_{\mathrm{Si}}<\mathrm{C}^{*}{ }_{\mathrm{Si} \text {,pr. This }}$ is the case, when the Si concentration in solution reaches the threshold value of $\mathrm{C}_{\mathrm{Si} \text {,set }}^{*}$, IDB forms without formation of precipitation minerals. These conditions usually occur in borosilicate glasses, such as the well-studied glass R7T7 and its inactive form SON68. The rapid releasing of $\mathrm{B}$ and $\mathrm{Na}^{+}$leaves a porous, Si-rich phase, and the initially dissolved Si species supply material to form a condense-zone within the gel, called IDB. The morphological evolution of the IDB is related to both the water penetration into glass and the solubility of IDB itself. This condition was also presented in literatures[74,75], leaching of glass containing $0 \%$ and $2 \mathrm{~mol}^{2} \mathrm{ZrO}_{2}$. The sharp $\mathrm{B}$ and $\mathrm{Na}$ profiles at initial stages pointed out that the soluble cations were free to diffuse toward solution as the IDB was not formed, and the quite soft profiles profiles of $\mathrm{B}$ and $\mathrm{Na}$ could due to the formation and evolution of IDB after a certain time interval. Obviously, $\mathrm{ZrO}_{2}$ content in glass has a significant effect on the formation and evolution of IDB, relates to the model parameters such as $\mathrm{C}_{\mathrm{Si} \text {,set }}, \mathrm{K}_{\mathrm{b}}$ and $\mathrm{D}^{\prime}$. This condition has been examined by Gin and other members of the same research team[51-53]. GM models have been found ill adapted to represent such a case, because they could neither describe the evolution of the IDB nor calculate the solubility of the IDB. This is the most favourable category, because such glasses undergo a low degree of corrosion even with a high initial dissolution rate. Sometimes, a very slow alteration rate can be expected[53]. In this condition, when Si distribution between IDB and solution reaches equilibrium, the final Si concentration is controlled by the solubility of IDB and the residual rate is controlled mainly by reaction diffusion, with a diffusion coefficient that depends directly on the properties of the IDB, thus on glass composition and leaching conditions. Usually a maximum protective property can be expected according to Rebiscoul[52, 53], resulting in a final water diffusion coefficient.

Category 4: $\mathrm{C}_{\mathrm{Si} \text {,set }}^{*}<\mathrm{C}_{\mathrm{Si} \text {,pr }}^{*}<\mathrm{C}_{\mathrm{Si}}^{*}$ or $\mathrm{C}_{\mathrm{Si} \text {,pr }}^{*}<\mathrm{C}_{\mathrm{Si} \text {,set }}^{*}<\mathrm{C}_{\mathrm{Si}}^{*}$. This caseis potentially the most complex and can be further divided into two sub-categories. For example, if $\mathrm{C}_{\mathrm{Si} \text {,set }}^{*}<$ $\mathrm{C}^{*}{ }_{\mathrm{Si} \text {,pr }}<\mathrm{C}_{\mathrm{Si}}^{*}$, when the concentration of $\mathrm{Si}$ in solution $\mathrm{C}_{\mathrm{Si}}(\mathrm{t})$ reaches the threshold value $\mathrm{C}_{\mathrm{Si} \text {,set }}^{*}$, IDB is formed. At the very beginning of IDB formation, $X\left(1-\frac{C_{S i}(t)}{C_{S i}^{*}}\right)>Y\left(\frac{C_{S i}(t)}{C_{S i, s e t}^{*}}-1\right)$, which means $\mathrm{dC}_{\mathrm{Si}}(\mathrm{t})>0$, the concentration of $\mathrm{Si}$ in solution will keep increasing until $X\left(1-\frac{C_{S i}(t)}{C_{S i}^{*}}\right)$ $=Y\left(\frac{C_{S i}(t)}{C_{S i, s e t}^{*}}-1\right)$, i.e $\mathrm{C}_{\mathrm{Si}}(\mathrm{t})=(X+Y) /\left(X / \mathrm{C}_{\mathrm{Si}}^{*}+Y / \mathrm{C}_{\mathrm{Si} \text {,set }}^{*}\right)$. Here two situations may follow: (a) If $(X+Y) /\left(X / \mathrm{C}_{\mathrm{Si}}^{*}+Y / \mathrm{C}_{\mathrm{Si}, \mathrm{set}}^{*}\right)<\mathrm{C}_{\mathrm{Si}, \mathrm{pr}}^{*}$, the solution reaches steady-state but the concentration of $\mathrm{Si}$ is still lower than the threshold value to form secondary precipitation. The phenomenon would be just the same as Category $3,\left(\mathrm{C}_{\mathrm{Si} \text {, set }}^{*}<\mathrm{C}^{*}{ }_{\mathrm{Si}}<\mathrm{C}^{*} \mathrm{Si}\right.$, pr $)$, i.e. IDB formed, but without any precipitation minerals; (b) If $(X+Y) /\left(X / \mathrm{C}^{*}{ }_{\mathrm{Si}}+Y / \mathrm{C}^{*}{ }_{\mathrm{Si}}\right.$, set $)>\mathrm{C}^{*} \mathrm{Si}$, pr, secondary minerals can be formed before solution reached steady-state. Under this condition, both IDB and secondary minerals formed and developed. This is an open argument for both chemical 
affinity mechanism and diffusion barrier mechanism. In fact, both mechanisms are important. The final concentration of $\mathrm{Si}$ in solution is controlled by precipitation of minerals and evolution of IDB, together with dissolution of IDB. The distribution of $\mathrm{Si}$ in solution is competed by evolution of IDB and precipitation of secondary minerals. The competition depends on Si properties, presented by its characteristic parameters - kinetic parameters $\mathrm{k}_{\mathrm{b}}, \mathrm{k}^{\prime}$ and thermodynamic parameter $C^{*}{ }_{\text {Si,set }}, C^{*}{ }_{\text {Si,pr. When the }} Y\left(\frac{C_{S i}(t)}{C_{S i, s e t}^{*}}-1\right)>Z\left(\frac{C_{S i}(t)}{C_{S i, p r}^{*}}-1\right)$, the Si species in solution are mainly supplied to IDB, resulting in decreased release rate of B and $\mathrm{Na}$, as well as $\mathrm{Si}$. Otherwise, the $\mathrm{Si}$ species in solution are mainly supplied to precipitation minerals, resulting in increased release rate of $\mathrm{Si}, \mathrm{B}$ and $\mathrm{Na}$. When $(X+Y+Z)=\left(X / \mathrm{C}_{\mathrm{Si}}^{*}+\right.$ $Y / \mathrm{C}_{\mathrm{Si} \text {,set }}^{*} \mathrm{Z} / \mathrm{C}_{\mathrm{Si} \text {,pr }}^{*} \mathrm{C}_{\mathrm{Si}}(\mathrm{t})$, the system is in a steady-state(residual regime), for which a relatively constant $\mathbf{r}_{\text {final }}$ of $\mathrm{Si}$ (case 2)and a constant water diffusion coefficient(case 3) would be observed simultaneously(see Fig.3, Category 4). Unfortunately, in batch systems it is often very difficult to distinguish between diffusion-limited and near-equilibrium dissolution rates. This may be one of the main reasons why such a category has been overlooked to date.
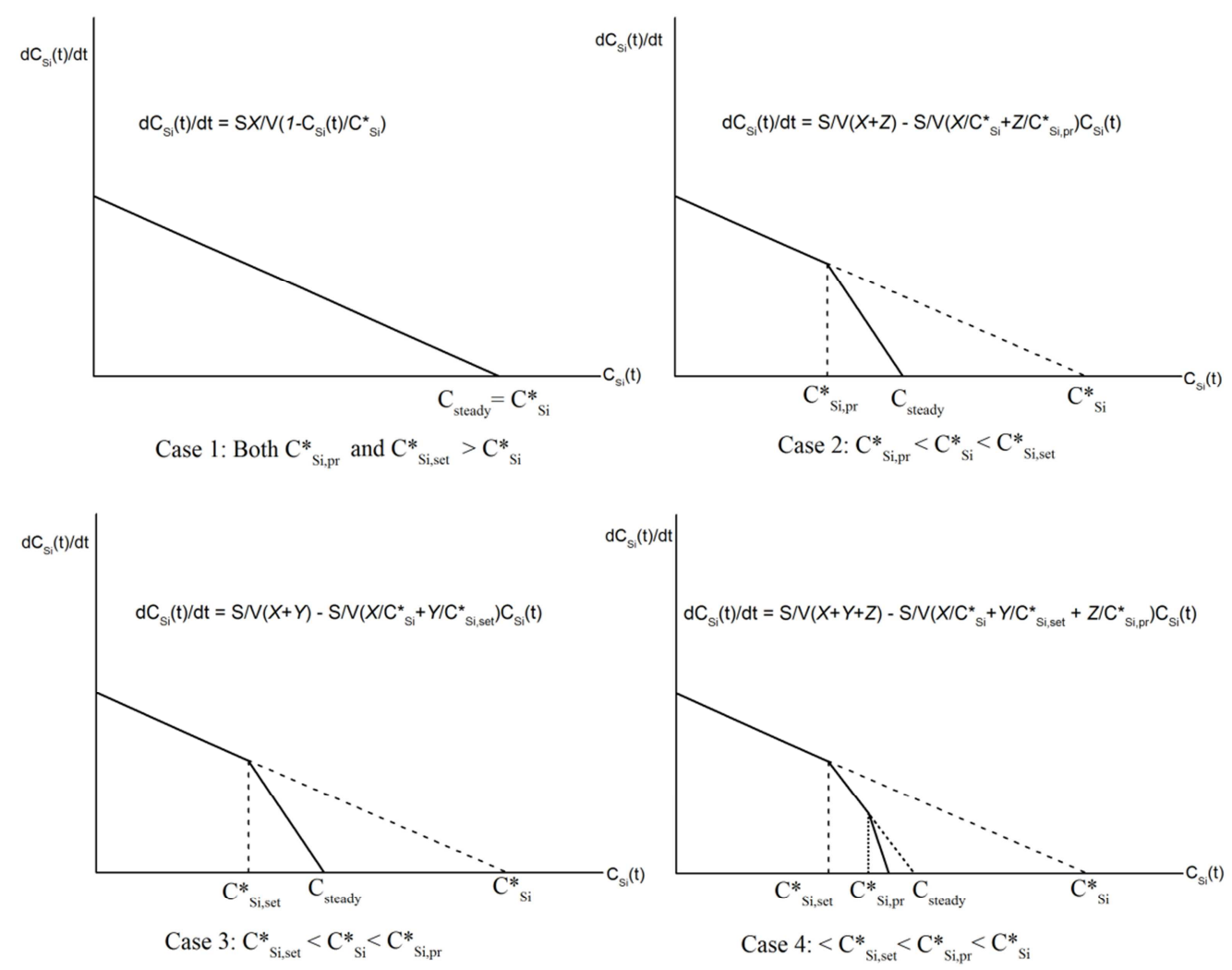

Fig.3. Illustration of four glass dissolution categories. $\mathrm{X}$ axis is Si concentration( arbitrary units), and $\mathrm{Y}$ axis is $\mathrm{dC}_{\mathrm{Si}}(\mathrm{t}) / \mathrm{dt}$ (also arbitrary units). This figure shows that how $\mathrm{dC}_{\mathrm{Si}}(\mathrm{t}) / \mathrm{dt}$ changes versus Si concentration in solution, the inflexions of line implies the changing of kinetic regimes and relate to certain model parameters

4.2.2 Further corrosion of glasses in different alteration degree 
Sometimes, researchers change the leaching conditions abruptly to test the robustness of their models. This method can help validate and improve the models.

(1) Pristine glass altered in saturated water

A number of experiments have been performed where pristine glass is altered in saturation solution to underline deficiencies on the chemical affinity models. Fresh glass is exposed to solutions which have been used in a previous powder glass dissolution test, hence saturated with dissolved glass constituents. A simple first-order dissolution rate law would assume that the glass water reaction should stop because the solution is saturated. The experiment would show that glass corrosion rates are only slightly lower than the initial rate [14].GM models explain this observation by considering the pre-alteration as continuous experiment with a discontinuous interpretation of model results, pre-alteration can be regarded as a continuous experiment with a discontinuous interpretation of model results. For example, if the effect of 10-day pre-alteration on 90-day glass alteration under saturated conditions were to be calculated, one would make a calculation for 100 days and subtract the initial 10 days result. But, this method works only under saturation conditions and based on a unique set of parameters. The model proposed here offers a different explanation. Firstly, Si concentration under steady-state conditions is not considered equal to $\mathrm{Si}$ saturation concentration. According to Eq.(16) chemical affinity is larger than zero so that it can support the precipitation of minerals and evolution of IDB. When the three reactions approach equilibrium, the Si concentration approaches a constant value, called here steady-state value, not saturation. The steady-state value must be lower than saturation value(see Fig.3); the difference between the two depends on the properties of precipitation minerals and IDB, thus, depends on the glass composition and leaching conditions. This suggests that previous use of steady-state and saturation concentrations as equivalent is not accurate. Secondly, altered glass has quite different properties from pristine glass, especially surface properties. When a pristine glass contacts water, initially chemical affinity relates to the properties of pristine glass, i.e. at this stage the saturation parameter should be $\mathrm{C}^{*}{ }_{\mathrm{Si} \text {,glass }}$. When the system reaches steady-state, the equilibrium is established between IDB and solution, i.e. at this stage the saturation parameter should be $\mathrm{C}_{\mathrm{Si}, \mathrm{IDB}}^{*}$. As IDB is a stable product of pristine glass in solution,

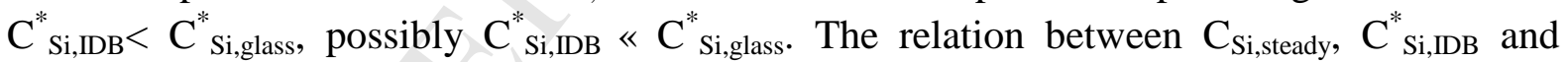
$\mathrm{C}_{\text {Si,glass }}^{*}$ should be $\mathrm{C}_{\mathrm{Si} \text {,steady }}<\mathrm{C}_{\mathrm{Si}, \mathrm{IDB}}^{*}$ « $\mathrm{C}_{\text {Si,glass }}^{*}$. Regarding the experiment of pristine glass altered in saturated solution, the proposed model states that the initial rate is $r^{0}\left(1-\mathrm{C}_{\mathrm{Si} \text {,steady }} /\right.$ $\mathrm{C}^{*}{ }_{\mathrm{Si} \text {,glass }}$ ), only slightly lower than $\mathrm{r}^{0}$,in agreement with the experimental observations.

(2) Pre-altered glass altered in pure water

When pre-altered glass is exposed to solutions without or with low Si concentration, a simple first-order law would assume that resumption of the glass dissolution should be observed, but in fact, the rate of dissolution is a function of pre-alteration time. Rebiscoul[53] performed a study of this scenario and argued that the protective properties and stability depended on the gel morphology and on the glass composition and increased with the alteration progress. The renewal of the solution did not decrease the protective properties of the IDB. As discussed above, pre-altered glass has different properties from pristine glass. Equilibrium is established between IDB and the solution at high alteration progress, as pointed out by Rebiscoul, Si is released from the gel, not from pristine glass. IDB is the stable 
product of metastable glass; the bonds of IDB are reorganized by hydrated glass which is depleted in B and alkalis. In line with basic thermodynamics, bonds of IDB are much stronger than those in pristine glass; $\mathrm{r}^{0}$ is no longer suitable to describe the initial dissolution rate, because $r^{0}$ is related the pristine glass, not IDB. A new parameter $r^{\text {IDB }}$ should be defined as the initial rate of IDB which relates to the properties of IDB, $r^{\mathrm{IDB}}<r^{0}$.Using the model proposed here, the rate of pre-altered glass exposed to water can be expressed as $r=r^{\mathrm{IDB}}(1$ $\mathrm{C}_{\mathrm{Si}}(\mathrm{t}) / \mathrm{C}_{\mathrm{Si}, \mathrm{IDB}}^{*}$ ). Rebiscoul argues that the gel can restore its protective properties after the solution renewal, i.e. this perturbation does not decrease the protective properties of the gel. According to the proposed model, the IDB can be dissolved, but at a relatively low rate. If the dissolution time is sufficient, the IDB can be destroyed and lose its protective properties. Then the release of glass modifiers $\mathrm{B}$ and $\mathrm{Na}$ will resume until a new equilibrium is reached.

\subsubsection{Rules of key elements release from glass during leaching time}

There are already a lot of experimental date in published papers. Generally, the researchers try to find a law to describe the glass dissolution behaviour. But the wide range of glass compositions studied and the variable test conditions make it rather difficult to achieve this goal, because sometimes the experimental date and observations can be misleading. In this section, we try to clarify the rules of main elements releasing from glass.

(1) Evolution of Si concentration in solution

For static experiments(As in this condition, released components can be accumulated in solution, make it easier to compile the date and obtain main mechanisms), if the leaching time is long enough, the concentration of $\mathrm{Si}$ would finally obtain a constant value, i.e. steadystate concentration[61, 62, 74, 75]. Take case 3 in section 4.2.1 as an example, according to equation (16), the evolution of $\mathrm{Si}$ concentration in solution can be divided into two stages, when $\mathrm{C}_{\mathrm{Si}}(\mathrm{t})<\mathrm{C}_{\mathrm{Si} \text {,set }}^{*}, \mathrm{C}_{\mathrm{Si}}(\mathrm{t})$ can be described as:

$$
\mathrm{C}_{S i}(\mathrm{t})=\mathrm{C}_{0} \exp \left(-\frac{\mathrm{s}}{\mathrm{V}} \times \frac{\mathrm{x}}{\mathrm{C}_{\mathrm{Si}}^{*}} \mathrm{t}\right)+\mathrm{C}_{\mathrm{Si}}^{*}
$$

Where $\mathrm{C}_{0}$ is a constant number determined by boundary condition. If glass was leached in the pure water with no $\mathrm{Si}$ in initial aqueous system, i.e, $\mathrm{t}=0, \mathrm{C}_{\mathrm{Si}}(\mathrm{t})=0$, thus $\mathrm{C}_{0}=\mathrm{C}_{\mathrm{Si}}^{*}$. Equation (22) can be simplified as:

$$
\mathrm{C}_{\mathrm{Si}}(\mathrm{t})=\mathrm{C}_{\mathrm{Si}}^{*}\left[1-\exp \left(-\frac{\mathrm{s}}{\mathrm{V}} \times \frac{\mathrm{x}}{\mathrm{C}_{\mathrm{Si}}^{*}} \mathrm{t}\right)\right]
$$

When $\mathrm{C}_{\mathrm{Si}}(\mathrm{t})=\mathrm{C}_{\mathrm{Si}, \mathrm{set}}^{*}$, relates to the characteristic time for formation of IDB, $\mathrm{t}_{1}$.

$$
\mathrm{t}_{1}=-\frac{\mathrm{v}}{\mathrm{S}} \times \frac{\mathrm{C}_{\mathrm{Si}}^{*}}{\mathrm{X}} \times \ln \left(1-\frac{\mathrm{C}_{\mathrm{Si}, \mathrm{set}}^{*}}{\mathrm{C}_{\mathrm{Si}}^{*}}\right)
$$

When $\mathrm{t}>\mathrm{t}_{1}$, the formation and evolution of IDB would change Si concentration curve, according to equation (16), in stage 2 , evolution of $\mathrm{Si}$ concentration can be described as:

$$
\mathrm{C}_{\mathrm{Si}}(\mathrm{t})=\mathrm{C}_{0} \exp \left[-\frac{\mathrm{s}}{\mathrm{V}} \times\left(\frac{\mathrm{X}}{\mathrm{C}_{\mathrm{Si}}^{*}}+\frac{\mathrm{Y}}{\mathrm{C}_{\mathrm{Si}, \text { set }}^{*}}\right)\left(\mathrm{t}-\mathrm{t}_{1}\right)\right]+\frac{\mathrm{X}+\mathrm{Y}}{\frac{\mathrm{X}}{\mathrm{C}_{\mathrm{Si}}^{*}+\frac{\mathrm{Y}}{\mathrm{C}_{\mathrm{Si}, \text { et }}^{*}}}}
$$


When $\mathrm{t}=\mathrm{t}_{1}, \mathrm{C}_{\mathrm{Si}}(\mathrm{t})=\mathrm{C}_{\mathrm{Si} \text {,set }}^{*}, \mathrm{dC}_{\mathrm{Si}}(\mathrm{t}) / \mathrm{dt}=0$ denotes that the system reached steady-state, and:

$$
\mathrm{C}_{\mathrm{Si}, \text { steady }}=\frac{\mathrm{X}+\mathrm{Y}}{\frac{\mathrm{X}}{\mathrm{C}_{\mathrm{Si}}^{*}+\frac{\mathrm{Y}}{\mathrm{C}_{\mathrm{Si}, \mathrm{set}}^{*}}}}
$$

Equation(25) can be simplified as:

$$
\mathrm{C}_{\mathrm{Si}}(\mathrm{t})=\left(\mathrm{C}_{\mathrm{Si}, \mathrm{set}}^{*}-\mathrm{C}_{\mathrm{Si} \text {,steady }}\right) \exp \left[-\frac{\mathrm{s}}{\mathrm{V}} \times\left(\frac{\mathrm{X}}{\mathrm{C}_{\mathrm{Si}}^{*}}+\frac{\mathrm{Y}}{\mathrm{C}_{\mathrm{Si}, \text { set }}^{*}}\right)\left(\mathrm{t}-\mathrm{t}_{1}\right)\right]+\mathrm{C}_{\mathrm{Si} \text {,steady }}
$$

From mathematic point, although both(23) and(27) are exponential equations, but they are two different curve combined at time $t_{1}$ and constituted an integrated curve. Comparison with a single exponential equation(see equation 28) curve, with the precondition $\mathrm{C}_{\mathrm{Si} \text {,set }}^{*}<$ $\mathrm{C}_{\mathrm{Si} \text {,steady }}<\mathrm{C}_{\mathrm{Si}}^{*}$ as illustrated in Fig.3. The discrepancy between the integrated curve and the single exponential equation curve would be broader and broader during $0<\mathrm{t}_{\mathrm{t}}<\mathrm{t}_{1}$, but when $\mathrm{t}$ $>t_{1}$, this discrepancy would be narrower and narrower. During the whole leaching time, the integrated curve should be above over the single exponential equation curve. The two curve would approach to each other and to the same value, $\mathrm{C}_{\mathrm{Si} \text {,teady }}$.

$$
\mathrm{C}_{\mathrm{Si}}(\mathrm{t})=\mathrm{C}_{\mathrm{Si}, \text { steady }}\left\{1-\exp \left[-\frac{\mathrm{S}}{\mathrm{V}} \times\left(\frac{\mathrm{x}}{\mathrm{C}_{\mathrm{Si}}^{*}}+\frac{\mathrm{Y}}{\mathrm{C}_{\mathrm{Si}, \text { set }}^{*}}\right)\right] \mathrm{t}\right\}
$$

In fact, there is no difference between equation(28) and equation(41) in reference[14], which was proved to be well in agreement with experimental date. By carefully comparing the calculated values to experimental values( Fig.7 in reference 14), one can find that during the whole leaching time, the experimental date were slightly but systematically bigger than calculated values, and the discrepancy was bigger and bigger before $7 \mathrm{~d}$ (arbitrary estimated) but smaller and smaller after $7 \mathrm{~d}$. These observations are well in agreement with the mechanism assumption of model proposed by this paper. In addition, the Si concentration at $\mathrm{t}=\infty$ was not considered as "saturation" concentration but steady-state concentration.

Other cases also can be calculated by this model, and the Si concentration mainly follows exponential rules, the model parameters would depend on the glass composition as well as leaching conditions.

(2) Evolution of B concentration in solution

Unlike network-forming element $\mathrm{Si}$, the releasing of glass modifiers is controlled by diffusion mechanism. $\mathrm{B}$ is chosen as the glass tracer due to its negligible retention in alteration layer. But the evolution of B concentration in solution can be much complicated than Si. The rate of diffusion front is controlled by two parameters: diffusion coefficient, $\mathrm{D}_{\text {eff }}$ and diffusion distance, L. In the case of purely diffusive mechanism, the relation between diffusion distance, diffusion coefficient and time can be described as equation(29) and(30): 


$$
\begin{aligned}
& \mathrm{L}_{\mathrm{i}}=2 \sqrt{\frac{\mathrm{Dt}}{\pi}} \\
& \frac{\mathrm{d} \mathrm{L}_{\mathrm{i}}}{\mathrm{dt}}=\frac{2 \mathrm{D}}{\pi \mathrm{L}_{\mathrm{i}}}
\end{aligned}
$$

But in the case of glass dissolution, from equations(12) and(20), one can see that both of the two parameters strongly depend on the behaviours of Si species. So studying on the evolution of B concentration in solution must consider the state of Si phases at the same time. Based on existed observations, by comparing model equations(12) and(20) to pure diffusion equations(29) and(30), the model suggests five possibilities to classify the evolution of B concentration in solution(proportional to equivalent leaching thickness of $\mathrm{B}, \mathrm{L}_{\mathrm{B}}$ ):

(a) Congruent releasing with $\mathrm{Si}$

At the very beginning of dissolution, both $\mathrm{B}$ and $\mathrm{Si}$ would release from glass at their initial rate. if $\mathrm{dL}_{\mathrm{B}}(\mathrm{t}) / \mathrm{dt} \approx \mathrm{dL}_{\mathrm{Si}}(\mathrm{t}) / \mathrm{dt}$, According to model equation $(12), \mathrm{L}_{\mathrm{B}}(\mathrm{t})-\mathrm{L}_{\mathrm{Si}}(\mathrm{t}) \approx 0$, the diffusion distance wouldn't increase versus time, and B can maintain its initial rate. During the same time period, as Si concentration was far from saturation, Si also can maintain its initial rate for a certain time interval. Under this condition, B and Si would apparently reveal congruent dissolution behaviour(see Fig. 1 in reference 14, Fig. 3 in reference 48 and Fig. 1 in reference 61). This observation was often used for supporting "congruent dissolution" assumption, but it was not a universal observation. If the concentration of $\mathrm{Si}$ in solution was high enough, $\mathrm{dL}_{\mathrm{B}}(\mathrm{t}) / \mathrm{dt}>\mathrm{dL}_{\mathrm{Si}}(\mathrm{t}) / \mathrm{dt}$, congruent dissolution would not sustain any more.

(b) Linear with $\mathrm{t}^{1 / 2}, \mathrm{~L}_{\mathrm{B}}=\mathrm{a} \mathrm{t}^{1 / 2}+\mathrm{b}$

As described in equations(29) and $(30), L_{B}(t)\left(\right.$ or $C_{B}(t)$ ) should be linear with $t^{1 / 2}$ in a pure diffusion law. Concerning model equations(12) and(20), if $\mathrm{dL}_{\mathrm{B}}(\mathrm{t}) / \mathrm{dt}>\mathrm{dL}_{\mathrm{Si}}(\mathrm{t}) / \mathrm{dt}$, and no IDB forms, thus $\mathrm{L}_{\mathrm{B}}(\mathrm{t})-\mathrm{L}_{\mathrm{Si}}(\mathrm{t}) \approx \mathrm{L}_{\mathrm{B}}(\mathrm{t})$ and $\mathrm{D}_{\text {eff }}$ remains in a constant value, $\mathrm{L}_{\mathrm{B}}$ can be linear with $t^{1 / 2}$, expressed as $L_{B}=a t^{1 / 2}+b$ (Fig. 4 in reference 17 and Fig6 in reference 59). This case can often be found when Si reached steady-state but without IDB formation(Fig.2, b in reference 75 ). This case can be used as evidence to validate the diffusion mechanism, because the effect of $\mathrm{Si}$ species on $\mathrm{L}_{\mathrm{B}}(\mathrm{t})$ can be negligible.

(c) Above $\mathrm{L}_{\mathrm{B}}=\mathrm{at} \mathrm{t}^{1 / 2}+\mathrm{b}$ regression

If $\mathrm{dL}_{\mathrm{B}}(\mathrm{t}) / \mathrm{dt}>\mathrm{dL} \mathrm{L}_{\mathrm{Si}}(\mathrm{t}) / \mathrm{dt}$, but $\mathrm{dL}_{\mathrm{Si}}(\mathrm{t}) / \mathrm{dt}$ can't be negligible, $\mathrm{L}_{\mathrm{B}}(\mathrm{t})-\mathrm{L}_{\mathrm{Si}}(\mathrm{t})<\mathrm{L}_{\mathrm{B}}(\mathrm{t})$, at the same time, $\mathrm{D}_{\text {eff }}$ remained in a relatively constant value, thus $\mathrm{dL}_{\mathrm{B}}(\mathrm{t}) / \mathrm{dt}=\mathrm{D}_{\text {eff }} /\left(\mathrm{L}_{\mathrm{B}}(\mathrm{t})-\mathrm{L}_{\mathrm{Si}}(\mathrm{t})\right)>$ $D_{\text {eff }} / L_{B}(t)$. This means the real diffusion rate is systematically bigger than a pure diffusion, resulting in a thicker $L_{B}$ than pure diffusion $\left(L_{B}=a t^{1 / 2}+b\right.$ regression). This case can be found when $\mathrm{C}_{\mathrm{Si}}$ didn't reach steady-state and also was not high enough to form IDB, at the same time, $\mathrm{dL}_{\mathrm{Si}}(\mathrm{t}) / \mathrm{dt}$ can't be negligible(Fig.5 in reference 17).

(d) Blow $\mathrm{L}_{\mathrm{B}}=\mathrm{at} \mathrm{t}^{1 / 2}+\mathrm{b}$ regression

This case can be commonly found in borosilicate glasses leaching experiments with IDB formed on the surface of glasses. If Si concentration in solution high enough to form IDB, although $\mathrm{dL}_{\mathrm{Si}}(\mathrm{t}) / \mathrm{dt}$ would be very small, but $\mathrm{D}_{\text {eff }}$ would decrease significantly because of the formation and evolution of IDB, thus $\mathrm{D}_{\text {eff }} /\left(\mathrm{L}_{\mathrm{B}}(\mathrm{t})-\mathrm{L}_{\mathrm{Si}}(\mathrm{t})\right)$ would also decrease significantly , then $L_{B}$ would be blow the $L_{B}=a t^{1 / 2}+b$ regression[14,48,51-53,74,75]. In some cases, the 
strongly protective properties of IDB can remain $D_{\text {eff }}$ at a sufficiently low value, thus the $\mathrm{dL}_{\mathrm{B}}(\mathrm{t}) / \mathrm{dt} \approx 0$, and $\mathrm{L}_{\mathrm{B}}$ apparently remain a constant thickness( Fig1 in reference 53 and Fig.2 in reference 75$)$.

(e) Linear with time t, $\mathrm{L}_{\mathrm{B}}=\mathrm{a} \mathrm{t}+\mathrm{b}$

If $\mathrm{dL}_{\mathrm{B}}(\mathrm{t}) / \mathrm{dt}>d \mathrm{~L}_{\mathrm{Si}}(\mathrm{t}) / \mathrm{dt}, \mathrm{L}_{\mathrm{B}}(\mathrm{t})-\mathrm{L}_{\mathrm{Si}}(\mathrm{t})<\mathrm{L}_{\mathrm{B}}(\mathrm{t})$, the diffusion distance of $\mathrm{B}$ would increase continuously, result in a continuously decreasing of diffusion rate, $\mathrm{dL}_{\mathrm{B}}(\mathrm{t}) / \mathrm{dt}$. Consider the case 2 discussed in section 4.2.1, $\mathrm{dL}_{\mathrm{Si}}(\mathrm{t}) / \mathrm{dt}$ would finally reach a constant value. The continuously decreasing diffusion rate of $\mathrm{B} \mathrm{dL}(\mathrm{t}) / \mathrm{dt}$ would approach this $\mathrm{dL}_{\mathrm{Si}}(\mathrm{t}) / \mathrm{dt}$ constant value. In particular case, it is possible that if $\mathrm{dL}_{\mathrm{B}}(\mathrm{t}) / \mathrm{dt}$ close enough to $\mathrm{dL}_{\mathrm{Si}}(\mathrm{t}) / \mathrm{dt}, \mathrm{L}_{\mathrm{B}}(\mathrm{t})-\mathrm{L}_{\mathrm{Si}}(\mathrm{t})$ also can remain in a constant value. At the same time, if there was no IDB or the protective properties of $\mathrm{Si}$ phases can be negligible, $\mathrm{D}_{\text {eff }}$ would also remain in a constant value. $\mathrm{D}_{\text {eff }} /\left(\mathrm{L}_{\mathrm{B}}(\mathrm{t})-\mathrm{L}_{\mathrm{Si}}(\mathrm{t})\right)$ can remain in constant value, $\mathrm{L}_{\mathrm{B}}$ would be linear with time, and can be expressed as $\mathrm{L}_{\mathrm{B}}=\mathrm{a} \mathrm{t}+\mathrm{b}$. This observation perhaps can't commonly found, but it is really possible in theory.

\subsection{Recommendations}

The main purpose of this paper is proposing an alternative viewpoint about the mechanisms controlling the dissolution of glass in solution, and establishing mathematic equations to describe these mechanisms. Generally, the release of glass modifiers were controlled by diffusion and the release of network-forming elements(especially $\mathrm{Si}$ ) were controlled by chemical affinity, but the two mechanisms have significant effect on each other.

First, the model emphasizes the IDB, which has key effect on both diffusion and the chemical affinity. Researchers from Marcoule Laboratory had done a lot of work on the protective alteration layer and made great progresses[14,15,48,51-53,64,65]. But still, much work needs to be done further. For example, the effect of glass composition, leaching conditions such as temperature, $\mathrm{pH}$, Eh, ion strength, $\mathrm{S} / \mathrm{V}$ on the formation and evolution of IDB need to be systematically investigated to obtain a comprehensive understanding of IDB. The relation between IDB protective properties and thickness, density, structure also need to be further studied.

Second, the model emphasizes the formation and evolution of secondary precipitation minerals. Such minerals perhaps are the key factor which would determine the glass dissolution remaining in "residual rate" regime or "resumption of alteration" regime. During glass alteration, the formation of clay mineral assemblages on the leached glass surface layers caused the dissolution rate to remain in a long term residual rate, but the formation of zeolite mineral assemblages on the leached glass surface layers caused the dissolution rate to increase and return to the initial high forward rate[27,76]. But the formation mechanisms and conditions are not fully studied. Sometime, even observing and identifying of such secondary phases are difficult due to its extremely small crystals. Leaching experiments, geochemical simulation codes(like EQ3/6) together with instrumental techniques should be employed to systematically study the formation mechanisms of secondary precipitation minerals:(1) in what conditions would clay mineral assemblages form;(2) in what conditions would zeolite mineral assemblages form;(3) how do the factors such as glass composition, solution 
chemistry, $\mathrm{pH}$, temperature, $\mathrm{S} / \mathrm{V}$ effect on the formation of secondary minerals and how to describe these factors suitably in mathematic equations.

\section{Conclusion}

A strongly mechanistic model for calculation of long-term glass dissolution is proposed. The model is based on a combination of the two most competitive mechanisms at present: chemical affinity and diffusion barrier. For a long time, researchers argued about which mechanism was dominant in the rate drop and residual rate regimes of glass dissolution. The alternative proposed here is that the two mechanisms are not contradicting, but controlling different types of reaction taking place concurrently during glass dissolution:(1) water diffusion controlling the reactions that occur rapidly, such as ion-exchange and reactive diffusion, thus controlling the release rate of glass modifiers (like B and alkalis);(2) chemical affinity controlling the distribution of $\mathrm{Si}$ among different alteration phases, where rupture and reformation of network(glass, IDB or precipitation minerals), bridging bonds Si-O-M(i.e covalent bonds containing the main element $\mathrm{Si}$ ) are all assumed as elemental reactions. The two mechanisms not only control different types of reaction, but also affect each other. For example, rupture and reformation of covalent bonds Si-O-M affects water diffusion, since it can build up a diffusion barrier between the pristine glass and solution, limiting the mass exchange between the two phases. The proposed model divides glass dissolution behaviours into four categories. Realisation of particular behaviour depends on the composition and leaching conditions, represented by model parameters. The four categories can provide explanations of experimental observations that cannot be well interpreted by the models based solely on chemical affinity or diffusion barrier. Particularly, it is shown how the model explains glass dissolution in special conditions, such as pristine glass altered in saturated water and pre-altered glass altered in pure water. The model is sufficiently flexible to allow for testing various hypotheses for long-term glass alteration not only by parameter calibration, but also by introducing new mechanisms. For one example, at present, it is difficult to model the resumption of nuclear glass alteration, because the newly formed phases(namely zeolites and calcium silicate hydrates) and their nucleation-growth mechanism are not fully investigated, if some new mechanisms were verified, we can build up additional model equations, relate such mechanisms to the model parameters such as $\mathrm{D}^{\prime}$ and $L_{\mathrm{IDB}}(t)$, thus the model can cover regime $\mathrm{V}$ (resumption of nuclear glass alteration) suitably. For another example, $\mathrm{Zr}$ was found to be important on the formation of IDB[74, 75]. If the relation between $\mathrm{Zr}$ fraction and threshold of IDB formation $\mathrm{C}^{*}$ Si,set were calibrated, then parameter $\mathrm{C}_{\mathrm{Si} \text {,set }}^{*}$ could be expressed in the term of $\mathrm{x}_{\mathrm{Zr}}$, thus improving the model predictive capability.

\section{References:}

[1] McKinley I G, The management of long lived nuclear waste, ENERGY POLICY 20(1992) 683-692

[2] Poinssot C, Gin S, Long-term Behaviour Science: The cornerstone approach for reliably assessing the longterm performance of nuclear waste, Journal of Nuclear Materials 420(2012) 182-192

[3] Bennett D G, Gens R. Overview of European concepts for high-level waste and spent fuel disposal with special reference waste container corrosion, Journal of Nuclear Materials 379(2008) 1-8

[4] Campbell J E, Cranwell R M. Performance Assessment of Radioactive Waste Repositories, Science 239(1988) 1389-1392

[5] Ojovan M I, Lee W E, Glassy Wasteforms for Nuclear Waste Immobilization, METALLURGICAL AND MATERIALS TRANSACTIONS A 42(2011)837-851 
[6] Criscenti L J, Schultz P A, Steefel C, Zapol P, Bourg I, Progress toward Bridging from Atomistic to Continuum Modeling to Predict Nuclear Waste Glass Dissolution, Sandia Report, SAND2011-8250, Sandia National Laboratories, 2011

[7] Carron A V, Gin S, Libourel G, Archaeological analogues and the future of nuclear waste glass, Journal of Nuclear Materials 46(2010) 365-370

[8] Libourel G, Carron A V, Morlok A, Gin S, Sterpenich J, Michelin A, Neff D, Dillmann P, The use of natural and archeological analogues for understanding the long-term behaviour of nuclear glasses, C. R. Geoscience.343(2011) 237-245

[9] Jantzen C M, Brown K G, Pickett J B, Durable Glass for Thousands of Years, International Journal of Applied Glass Science1(2010) 38-62

[10] Crovisier J L, Advocat T, Dussossoy J L, Nature and role of natural alteration gels formed on the surface of ancient volcanic glasses, Journal of Nuclear Materials 321(2003) 91-109

[11] Petit J C, Reasoning by analogy: rational foundation of natural analogue studies, Applied Geochemistry 7(1992) 9-11

[12] Gin S, Abdelouas A, Criscenti L J, Ebert W L, Ferrand K, Geisler T, Harrison M T, Inagaki Y, Mitsui S, Mueller K T, Marra J C, Pantano C G, Pierce E M,An international initiative on long-term behaviour on highlevel nuclear glass, Materials Today 16(2013) 243-248

[13] Grambow B, Müller R, First-order dissolution rate law and the role of surface layers in glass performance assessment, Journal of Nuclear Materials298(2001) 112-124

[14] Jégou C, Gin S, Larché F, Alteration kinetics of a simplified nuclear glass in an aqueous medium: effects of solution chemistry and of protective gel properties on diminishing the alteration rate, J. Nucl. Mater. 280(2000) 216-229

[15] Chave T, Frugier P, Ayral A, Gin S, Solid state diffusion during nuclear glass residual alteration in solution, Journal of Nuclear Materials 362(2007) 466-473

[16] Utton C A , Hand R J , Bingham P A , Hyatt N C , Swanton S W , Williams S J , Dissolution of vitrified wastes in a high-pH calcium-rich solution, Journal of Nuclear Materials 435(2013) 112-122

[17] Frugier P, Gin S, Minet Y, Chave T, Bonin B, Godon N, Lartigue J E, Jollivet P, Ayral A, Windt L D, Santarini G, SON68 nuclear glass dissolution kinetics: Current state of knowledge and basis of the new GRAAL model, Journal of Nuclear Materials 380(2008) 8-21

[18] Davis K M, Tomozawa M, Water diffusion into silica glass: structural changes in silica glass and their effect on water solubility and diffusivity,Journal of Non-Crystalline Solids185(1995) 203-220

[19] Ferrand K, Abdelouas A, Grambow B, Water diffusion in the simulated French nuclear waste glass SON 68 contacting silica rich solutions: Experimental and modelling, Journal of Nuclear Materials 355(2006) 54-67

[20] Rébiscoul D, Rieutord F, NéF, Frugier P, Cubitt R, Gin S, Water penetration mechanisms in nuclear glasses by X-ray and neutron reflectometry, Journal of Non-Crystalline Solids 353(2007) 2221-2230

[21] Bunker B C, Molecular mechanisms for corrosion of Silica and silicate glasses, Journal of Non-Crystalline Solids, 179(1994) 300-308

[22] Minoru T, WATER IN GLASS, Journal of Non-Crystalline Solids 73(1985) 197-204

[23] Mc Grail B P,Icenhower J P,Shuh D K,Liu P et al., The structure of $\mathrm{Na}_{2} \mathrm{O}-\mathrm{Al}_{2} \mathrm{O}_{3}-\mathrm{SiO}_{2}$ glass: impact on sodium ion exchange in $\mathrm{H}_{2} \mathrm{O}$ and $\mathrm{D}_{2} \mathrm{O}$, Journal of Non-Crystalline Solids 296(2001)10-26

[24] Ojovan M I, Pankov A, Lee W E, The ion exchange phase in corrosion of nuclear waste glasses, Journal of Nuclear Materials 358(2006) 57-68

[25] Geneste G, Bouyer F, Gin S, Hydrogen-sodium interdiffusion in borosilicate glasses investigated from first principles, Journal of Non-Crystalline Solids 352(2006) 3147-3152.

[26] Bourcier W L, CRITICAL REVIEW OF GLASS PERFORMANCE MODELING, Argonne National Laboratory,Chemical Technology Division, ANL-94/17,1994

[27] Zavarin M, Roberts S K, Viani B E, Pawloski G A, Rose T P, Nuclear Melt Glass Dissolution and Secondary Mineral Precipitation at 40 to $200^{\circ} \mathrm{C}$, Lawrence Livermore National Laboratory report, UCRL-TR204870, 2004

[28] Criscenti L J, Kubicki J D, Brantley S L, Silicate Glass and Mineral Dissolution: Calculated Reaction Paths and Activation Energies for Hydrolysis of a $\mathrm{Q}^{3} \mathrm{Si}$ by $\mathrm{H}_{3} \mathrm{O}^{+}$Using Ab Initio Methods, J. Phys. Chem. A 110(2006) 198-206

[29] Morrow C P, Nangia S, Garrison B J, Ab Initio Investigation of Dissolution Mechanisms in Aluminosilicate Minerals, J. Phys. Chem. A113(2009) 1343-1352

[30] Nangia S, Garrison B J, Ab initio study of dissolution and precipitation reactions from the edge, kink, and terrace sites of quartz as a function of $\mathrm{pH}$, Molecular Physics107(2009) 831-843

[31] Nangia S, Garrison B J, Advanced Monte Carlo Approach To Study Evolution of Quartz Surface during the Dissolution Process, Journal of American Chemical Society 131(2009) 9538-9546 
[32] Pelmenschikov A, Strandh H, Pettersson L G M, Leszczynski J, Lattice Resistance to Hydrolysis of Si-O-Si Bonds of Silicate Minerals: Ab Initio Calculations of a Single Water Attack onto the (001) and (111) $\beta$ Cristobalite Surfaces, J. Phys. Chem. B 104(2000) 5779-5783

[33] Oelkers E H, General kinetic description of multioxide silicate mineral and glass dissolution, Geochimica et Cosmochimica Acta 65(2001) 3703-3719

[34] Hunter F M I, Hoch A R , Heath T G , Baston G M N, Review of glass dissolution models and application to UK glasses, Nuclear Decommissioning Authority 2015, RWM005105,U.K, 2015

[35] Paul A, Chemical durability of glasses: a thermodynamic approach, Journal of Material Science 12(1977) 2246-2268

[36] Jantzen C M, Plodinec M J, THERMODYNAMIC MODEL OF NATURAL, MEDIEVAL AND

NUCLEAR WASTE GLASS DURABILITY,Journal of Non-Crystalhne Solids 67(1984) 207-223

[37] Jantzen C M, Nuclear Waste Glass Durability: I, Predicting Environmental Response from

Thermodynamic (Pourbaix) Diagrams, J.Am.Ceram.Soc. 75(1992) 2433-2448

[38] Conradt R, A proposition for an improved theoretical treatment of the corrosion of multi-component glasses, Journal of Nuclear Materials 298(2001) 19-26

[39] Conradt R, Chemical structure, medium range order, and crystalline reference state of multicomponent oxide liquids and glasses, Journal of Non-Crystalline Solids(2004) 16-23

[40] Geisler T, Janssen A, Scheiter D, Stephan T, Berndt J, Putnis A, Aqueous corrosion of borosilicate glass under acidic conditions: A new corrosion mechanism, Journal of Non-Crystalline Solids 356(2010) 1458-1465 [41] Mellott, N P, Multicomonent Aluminosilicate Glasses: Structure and Acid Corrosion, Dissertation thesis, 180 p, The Pennsylvania State University University Park, PA, 2003

[42] Aagaard P , Helgeson H C, Thermodynamic and Kinetic Constraints on Reaction Rates Among Minerals and Aqueous Solutions, I. Theoretical Considerations, American Journal of Science 282(1982) 237-285

[43] Helgeson H C, Murphy W M, Aagaard P, Thermodynamic and kinetic constraints on reaction rates among minerals and aqueous solutions. II. Rate constants, effective surface area, and the hydrolysis of feldspar, Geochimica et Cosmochimica Acta 48(1984) 2405-2432

[44] Murphy W M, Helgeson H C, Thermodynamic and kinetic constraints on reaction rates among minerals and aqueous solutions. III. Activated complexes and the $\mathrm{pH}$-dependence of the rates of feldspar, pyroxene, wollastonite, and olivine hydrolysis, Geochimica et Cosmochimica Acta 51(1987) 3137-3153

[45] Grambow B, Nuclear Waste Glass Dissolution: Mechanism, Model and Application, Report to JSS Project, Phase IV, JSS-TR-87-02,1987

[46] Grambow B ,Strachan D M, A comparison of the performance of Nuclear Waste Glass by Modeling, Report of Pacific Northwest Laboratory, PNL-6698,1988

[47] Advocat T, Jollivet P, Minet Y, Luckscheiter B, Grambow B, Gens R, Lemmens K, Iseghem P V, Aertsens M, Pirlet V, Curti E, Experimental and modelling studies to formulate a nuclear waste glass source term in representative geological disposal conditions, EUROPEAN COMMISSION Community Research, EUR 19120,1999

[48] Ribet S, Gin S, Role of neoformed phases on the mechanisms controlling the resumption of SON68 glass alteration in alkaline media, Journal of Nuclear Materials 324(2004) 152-164

[49] Frugier P, Chave T, Gin S, Lartigue J E, Application of the GRAAL model to leaching experiments with SON68 nuclear glass in initially pure water, Journal of Nuclear Materials 392(2009) 552-567

[50] Minet Y, Bonin B, Gin S, Frugier P, Analytic implementation of the GRAAL model: Application to a R7T7-type glass package in a geological disposal environment, Journal of Nuclear Materials404(2010)178-202 [51] Gin S, Ribet I,Couillard M, Role and properties of the gel formed during nuclear glass alternation: importance of gel formations,Journal of Nuclear Materials298(2001) 1-10

[52] Rebiscoul D, Lee A V, Rieutord F, Né F, Spalla O, Mansouri A E, Frugier P, Ayral A, Gin S, Morphological evolution of alteration layers formed during nuclear glass alteration: new evidence of a gel as a diffusive barrier, Journal of Nuclear Materials326(2004) 9-18

[53] Rebiscoul D, Frugier P, Gin S, Ayral A, Protective properties and dissolution ability of the gel formed during nuclear glass alteration, Journal of Nuclear Materials342(2005) 26-34

[54] Valle N, Carron A V, Sterpenich J, Libourel G, Deloule E, Jollivet P, Elemental and isotopic $\left({ }^{29} \mathrm{Si}\right.$ and $\left.{ }^{18} \mathrm{O}\right)$ tracing of glass alteration mechanisms, Geochimica et Cosmochimica Acta(2010) 3412-3431

[55] Guittonneau C, Gin S, Godon N, Mestre J P, Dugne O, Allegri P, A 25-year laboratory experiment on French SON68 nuclear glass leached in a granitic environment - First investigations, Journal of Nuclear Materials, 408(2011) 73-89

[56] Grambow B, A General Rate Equation for Nuclear Waste Glass Crrosion, Mat.Res.Soc.Symp.Proc. 44(1985) 16-27 
[57] Curti E, Modelling the Dissolution of Borosilicate Glasses for Radioactive Waste Disposal with the PHREEQE/GLASSOL Code: Theory and Practice, Paul Scherrer Institute Report PSI-Bericht Nr. 86, Wiirlingen, Switzerland, 1991

[58] Van Iseghem P, Aertsens M, Gin S, Deneele D, Grambow B, McGrail P, Strachan D, Wicks G, A Critical Evaluation of the Dissolution Mechanisms of High-level Waste Glasses in Conditions of Relevance for Geological Disposal(GLAMOR), EUROPEAN COMMISSION, EUR 23097, 2007

[59] Neeway J, Abdelouas A, Grambow B, Schumacher S, Dissolution mechanism of the SON68 reference nuclear waste glass: New data in dynamic system in silica saturation conditions, Journal of Nuclear Materials 415(2011) 31-37

[60] Gin S, Jégou C, Frugier P, Minet Y, Theoretical consideration on the application of the Aagaard-Helgeson rate law to the dissolution of silicate minerals and glasses, Chemical Geology 255(2008) 14-24

[61] Ledieu A, Devreux F , Barboux P, Sicard L, Spalla O, Leaching of borosilicate glasses. I. Experiments, Journal of Non-Crystalline Solids 343(2004) 3-12

[62] Devreux F, Ledieu A, Barboux P, Minet Y, Leaching of borosilicate glasses. II. Model and Monte-Carlo simulations, Journal of Non-Crystalline Solids343(2004) 13-25

[63] Icenhower J P, McGrail P B, Shaw W J, Pierce E M, Nachimuthu P, Shuh D K, Rodriguez E A, Steele J L, Experimentally determined dissolution kinetics of Na-rich borosilicate glass at far from equilibrium conditions: Implications for Transition State Theory, Geochimica et Cosmochimica Acta 72(2008) 2767-2788

[64] Gin S, Jollivet P, Fournier M, Angeli F, Frugier P, Charpentier T, Origin and consequences of silicate glass passivation by surface layers, NATURE COMMUNICATIONS,6:6360(2015) 1-8

[65] Gin S, Neill L, Fournier M, Frugier P, Ducasse T, Tribet M, Abdelouas A, Parruzot B, Neeway J, Wall N. The controversial role of inter-diffusion in glass alteration, Chemical Geology 440(2016) 115-123

[66] Frugier P, Martin C, Ribet I, Advocat T, Gin S, The effect of composition on the leaching of three nuclear waste glasses: R7T7, AVM and VRZ, Journal of Nuclear Materials346(2005) 194-207

[67] Hamilton J P, Brantley S L,Pantano C G, Criscenti L J, Kubicki J D, Dissolution of nepheline, jadeite and albite glasses: Toward better models for aluminosilicate dissolution, Geochimica et Cosmochimica Acta 65(2001) 3683-3702

[68] Roland H, Richard W, Damien D, Jean P B, Jean M P,Delphine T, Thierry E, Brigitte F, Richard L H, Unifying natural and laboratory chemical weathering with interfacial dissolution-reprecipitation: A study based on the nanometer-scale chemistry of fluid-silicate interfaces, Chemical Geology294-295(2012) 203-216

[69] Gan X Y, Zhang Z T, Yuan W Y, Wang L, Bai Y, Ma H, Long-term product consistency test of simulated 90-19/Nd HLW glass, Journal of Nuclear Materials 408(2011) 102-109

[70] Gin S, Mestre J P, SON68 nuclear glass alternation kinetics between pH 7 and pH 11.5, Journal of Nuclear Materials 295(2002) 83-96

[71] Fournier M, Gin S, Frugier P, Resumption of nuclear glass alteration: State of the art, Journal of Nuclear Materials 448(2014) 348-363

[72] Kerisit S, Pierce E M, Ryan J V,Monte Cerlo simulations of coupled diffusion and surface reactions during the aqueous corrosion of borosilicate glass, Journal of Non-Crystalline Solids 408(2015) 142-149

[73] Vienna J D, Ryan J V, Current Understanding and Remaining Challenges in Modeling Long-Term Degradation of Borosilicate Nuclear Waste Glasses, International Journal of Applied Glass Science, 4 [4] (2013)283-294

[74] Cailleteau C, Angeli F, Devreux F, Gin S, Jestin J, Jollivet P, Spalla O, Insight into silicate-glass corrosion mechanisms, Nature Materials 7(2008) 978-983

[75] Cailleteau C, Devreux F, Spalla O, Angeli F, Gin S, Why Do Certain Glasses with a High Dissolution Rate Undergo a Low Degree of Corrosion? The Journal of Physical Chemistry C 115(2011) 5846-5855

[76] Jantzen C M, Kaplan D I, Bibler N E, Peeler D K, Plodinec M J, Performance of a buried radioactive high level waste (HLW) glass after 24 years, Journal of Nuclear Materials 378(2008) 244-256 